\title{
Recent advances in the iron-catalyzed cycloaddition reactions
}

\author{
WANG ChunXiang \& WAN BoShun* \\ Dalian Institute of Chemical Physics, Chinese Academy of Sciences, Dalian 116023, China
}

Received December 19, 2011; accepted February 13, 2012; published online April 26, 2012

\begin{abstract}
The rapid generation of molecular in a relatively easy manner has made the cycloaddition reaction a powerful tool in the synthesis of different membered ring compounds. Clearly, iron catalysts are becoming a much more interesting and viable choice for this purpose. In this review, a number of promising results in the iron catalyzed cycloaddition reactions in the last decades were summarized. Special attention has been paid to the asymmetric cycloaddition reactions.
\end{abstract}

cycloaddition, iron catalyst, asymmetric

Citation: Wang C X, Wan B S. Recent advances in the iron-catalyzed cycloaddition reactions. Chin Sci Bull, 2012, 57: 2338-2351, doi: 10.1007/s11434-012-5141-z

Cycloaddition reaction, which can construct several bonds simultaneously in a single step, is one of the most powerful strategies for the synthesis of cyclic compounds from various unsaturated substrates such as alkynes, alkenes, allenes, nitriles, aldehydes, ketones, imines, etc. Three-, four-, five-, six- or seven-membered rings are obtained through these transformations. The high atom-efficiency, as well as the good tolerance of different functional groups, continues to draw many chemists' attention to this field. In particular, great efforts have been devoted to the development of novel and efficient catalytic systems. However, harsh reaction conditions are often required including heat, light, high pressure or sonication, and the lack of chemo- and/or regioselectivity is also an important problem. Over the past decades, the use of transition metal catalysts has contributed significantly to the development of the cycloaddition reactions and good selectivities were obtained [1].

Among all the available transition metals, iron is generally regarded as one of the most inexpensive, abundant, benign and relatively non-toxic metals [2]. Many transformations have been effectively promoted by iron catalysts, and excellent reviews on the iron-catalyzed reactions are available [3-15]. Bolm and co-workers [3] summarized the most important transformations with the aid of iron catalysts

*Corresponding author (email: bswan@dicp.ac.cn) in 2004, including addition, substitution, cycloaddition, reduction and other reactions. At a later time, they also reviewed the oxidative $\mathrm{C}-\mathrm{C}$ coupling reactions [4] and the development of carbon-heteroatom and heteroatom-heteroatom bond formation under iron catalysts [5]. The uses of $\mathrm{FeCl}_{3}$ as catalyst in organic synthesis were covered by Padrón [6] and Bolm [4], and the cross coupling reactions were discussed in detail by Fürstner [7,8]. Recently, direct $\mathrm{C}-\mathrm{H}$ transformation via iron catalysis was summarized by Shi and co-workers [9]. Applications of iron catalysts on other reactions were also summarized by Bauer [10], Enthaler [11], Nakamura [12], Liu [13] and Che [14] et al., respectively.

However, despite the aforementioned contributions, reviews mainly focus on the iron-catalyzed cycloaddition reactions are rather rare [15]. In this review, we will point out recent advances in this field, most contributions going from 2004 to Nov. 2011. Although every effort has been made to avoid repetition, some overlap with the contents in previous review sections $[3,14]$ or chapters of books [15] is still unavoidable.

\section{Iron-catalyzed cycloaddition reactions}

\subsection{Construction of three-membered rings}

$[2+1]$ cycloaddition reaction that combines an alkene and a 
diazo compound or nitrene fragment is an effective way to construct three-membered rings (cyclopropanes and aziridines, respectively, Scheme 1). The cyclopropanation and aziridination of alkenes have been recently reviewed by Zhou and co-workers [14] in two sections, and will be partly discussed here.

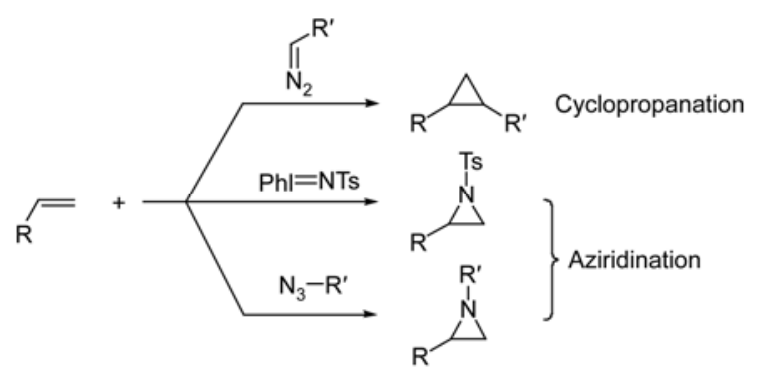

Scheme 1

Iron porphyrins (Scheme 2) are among the most efficient catalysts reported for the cyclopropanation of alkenes with diazo compounds. In 2001, Woo and co-workers [16] reported an efficient $\mathrm{Fe}$ (TTP)-catalyzed cyclopropanation of styrene with aryldiazomethanes. Interestingly, a reversal of diastereoselectivity was observed when different diazomethanes were employed (Scheme 3). For example, when $p$ tolyldiazomethane was subjected to this reaction, the corresponding product 1a was obtained in $79 \%$ yield with a high stereoselectiviy (trans: cis $=14: 1$ ), whereas a cis: trans ratio of $2: 1$ was found when bulkier mesityldiazomethane was used. In both cases, side product 2 was detected, in $21 \%$ and $40 \%$ yield, respectively.

A remarkable anti selectivity was observed by Tagliatesta et al. [17] using a bulkier iron porphyrin complex $\mathrm{Fe}(\mathrm{TDCPP}) \mathrm{Cl}$ (Scheme 4) with the aid of $\mathrm{CoCp}_{2}$. The

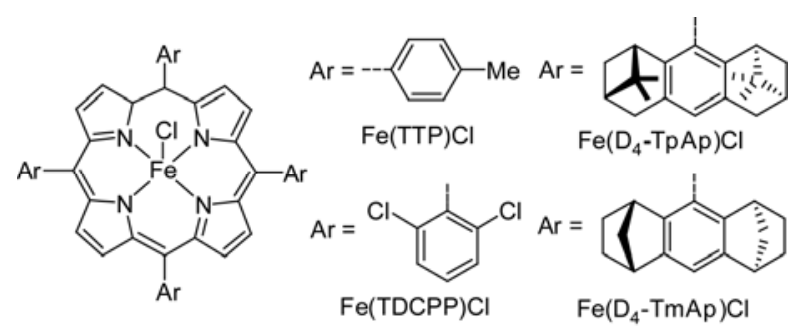

Scheme 2

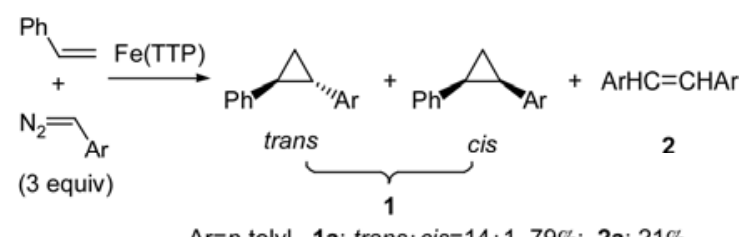

Ar=mesityl, 1b: trans: cis=1:2,60\%;2b:40\%

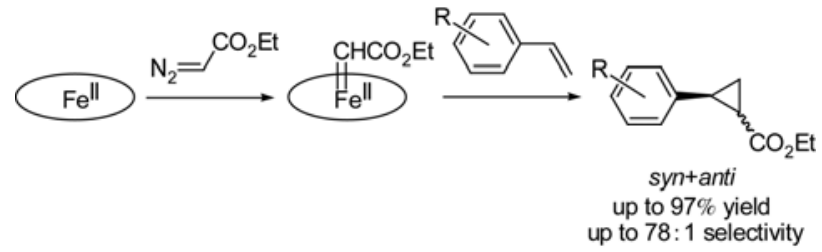

Scheme 4

cyclopropanation of various styrene derivatives and ethyldiazoacetate (EDA) afforded the desired products in high yields (up to 97\%) and excellent diastereoselectivity (trans: cis up to 78:1), and gave only the diethylmaleate as byproduct in much lower yields.

The asymmetric cyclopropanation of alkenes catalyzed by chiral iron porphyrin complexes was reported by Woo and co-workers [18] (Scheme 5). Iron complex with a $\mathrm{D}_{4^{-}}$ TPAP ligand gave high diastereoselctivity (trans: cis ratio up to $21: 1$ ) and moderate ee value for both diastereoisomers. Better diastereoselectivity (trans: cis ratio not less than 12 and up to 23) and higher enantioselectivity for trans-isomers (74\%-86\%) were observed by Lai et al. [19] using a similar iron porphyrin complexe $\left[\mathrm{Fe}\left(\mathrm{D}_{4}-\mathrm{TmAP}\right) \mathrm{Cl}\right.$ with Halterman's ligand. It is worthy to mention that the detection of $\left[(\mathrm{py}) \mathrm{Fe}\left(\mathrm{D}_{4}-\mathrm{TmAP}\right)\left(\mathrm{CHCO}_{2} \mathrm{Et}\right)\right]$ intermediate by ESMS in the latter case confirmed the active species in the catalytic cycle of alkene cyclopropanation.

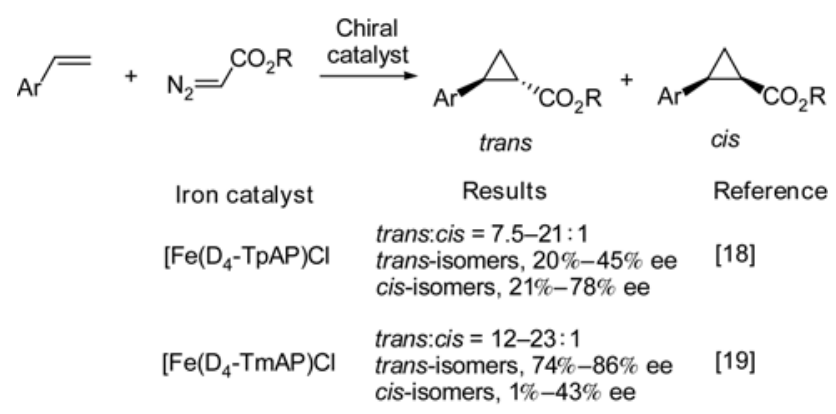

Scheme 5

Under the same iron catalyst, the asymmetric synthesis of cyclopropyl ketones [20] and trifluoromethylphenyl cyclopropanes [21] were accomplished by Simonneaux and coworkers with excellent anti selectivity and moderate to good enantioselectivity (Scheme 6). However, the carbene precursor trifluoromethyl diazomethane $\mathbf{3}$ is difficult to be handled because of its gaseous state at room temperature, and the synthetic method of $\mathbf{3}$ is still limited.

Recently, Carreira and co-workers [22] reported a practical method for the diastereoselective preparation of trifluoromethyl-substituted cyclopropanes in the presence of $\mathrm{Fe}$ (TTP) $\mathrm{Cl}$ in aqueous media. The active reagent $\mathbf{3}$ was generated in situ from $\mathrm{F}_{3} \mathrm{CCH}_{2} \mathrm{NH}_{2} \cdot \mathrm{HCl}$ and $\mathrm{H}^{+} / \mathrm{NaNO}_{2}$ in aqueous media. The corresponding cyclopropanes were obtained 


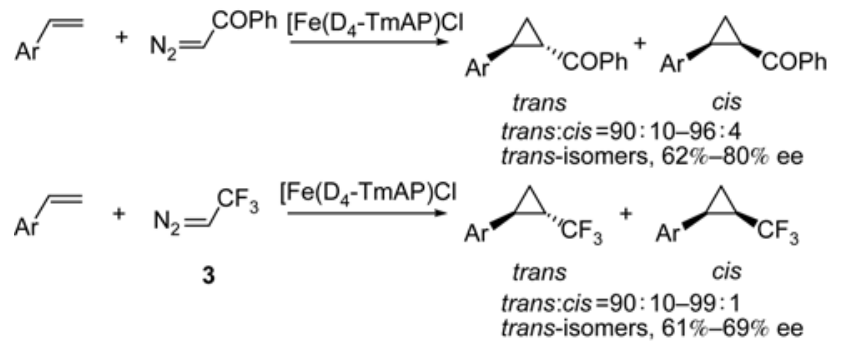

Scheme 6

in high yields as single trans diastereoisomers (Scheme 7). Only 1 equiv of alkene was required under the reaction conditions and the iron-porphyrin catalyst was compatible with the aqueous media. Further extension of this method to alkyl-substitued alkene only gave the product in $10 \%$ yield.

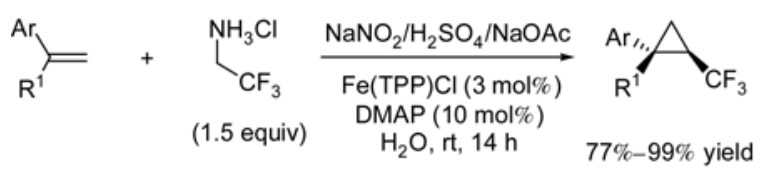

Scheme 7

More recently, an iron-catalyzed cyclopropanation to prepare trifluoromethyl substituted vinyl- and alkynylcyclopropanes was reported by the same authors using a similar procedure (Scheme 8) [23]. The amount of trifluoroethlyamine hydrochloride was adjusted to 2-4 equiv and the acid was not necessary. The cyclopropanes were obtained chemoselectively as single diastereoisomers and no biscyclopropanation products were observed.

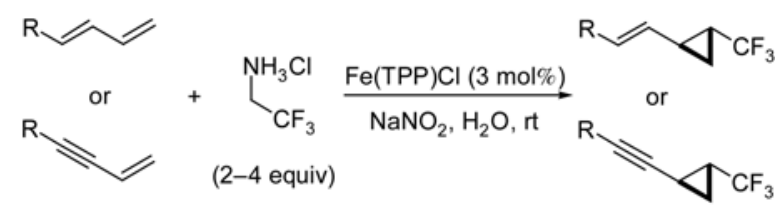

Scheme 8

Apart from the iron porphyrin complexes, air-stable $\mu$ oxo-bis[(salen)iron(III)] complexes (Scheme 9) were active

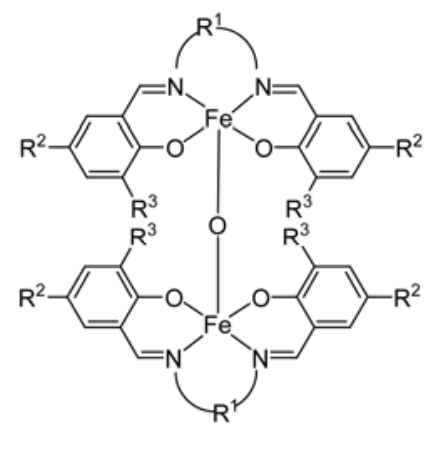

$\mu$-oxo-bis[(salen)iron(III)] catalysts for alkene cyclopropanation [24,25]. Moderate to good yields (19\%-97\%) and moderate diastereoselectivity (trans: cis $=1.7-4.0: 1$ ) were obtained for terminal olefins or even difficult internal olefins, such as trans- $\beta$-methyl styrene.

Since the first example of iron-catalyzed alkene azaridination reaction was reported by Mansuy et al. [26] using an iron porphyrin complex $\mathrm{Fe}(\mathrm{TTP}) \mathrm{Cl}$ as catalyst, the " $\mathrm{C}_{2}+\mathrm{N}_{1}$ " azaridination reactions have emerged in recent years. PhINTs was the most frequently used " $\mathrm{N}_{1}$ " source among the reported nitrene reagents. Compared with porphyrin compounds, phthalocyanines are much easier to access and more stable to degradation. Iron phthalocyanine complex 4 (Scheme 10) used as catalyst for the aziridination of alkenes and PhINTs was reported by Zhou and co-workers [27] in good yields with only slight excess of PhINTs (1.5 equiv). The iron Lewis acid $\left[\left(\eta^{5}-\mathrm{C}_{5} \mathrm{H}_{5}\right) \mathrm{Fe}(\mathrm{CO})_{2}(\mathrm{THF})\right]^{+}\left[\mathrm{BF}_{4}\right]^{-} \mathbf{5}$ also proved to be an efficient catalyst for the aziridination of styrene derivatives with PhINTs, as reported by Hossain and co-workers [28], affording the corresponding product with up to $85 \%$ yield (Scheme 11). Notablely, stereospecific products were obtained when internal alkenes were employed: cis- and trans-aziridines from cis- and trans-alkenes, respectively.

Non-heme iron complexes were also effective catalysts for aziridination of alkenes with PhINTs. Latour and coworkers [29] reported a dinuclear iron(II/III) complex 6 (Scheme 12) catalyzed arididination of styrene, cyclooctene and 1-hexene, however, only moderate yields were obtained even in the presence of a large excess of alkene (2000 equiv versus PhINTs). UV-visible monitoring and ESI-MS spectra

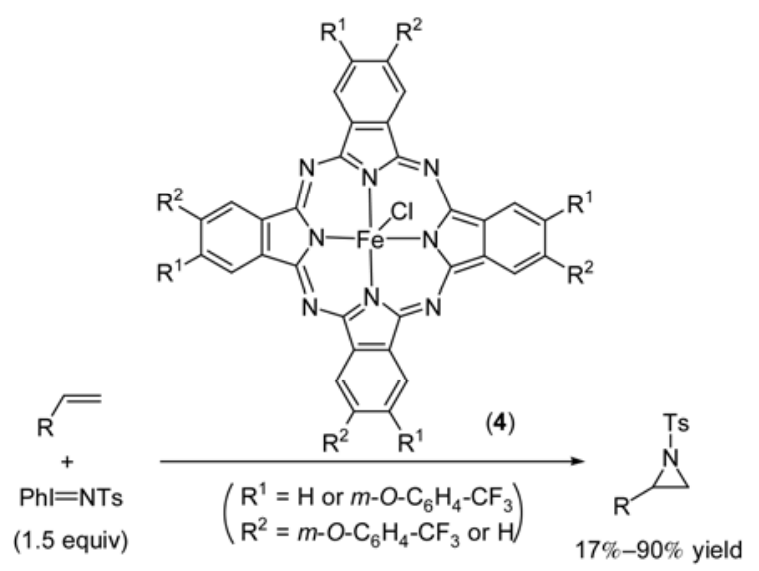

Scheme 10

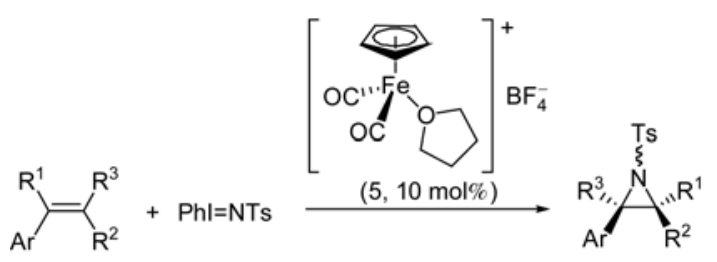

Scheme 11

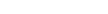




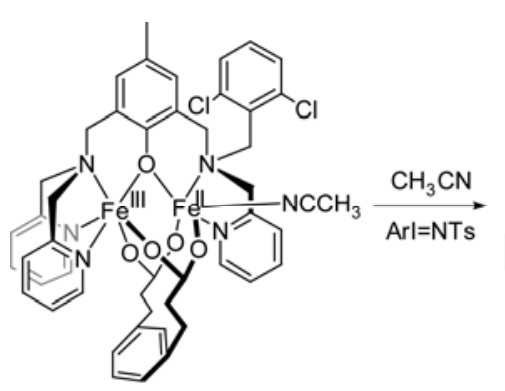

$\left[6\left(\mathrm{CH}_{3} \mathrm{CN}\right)\right]^{2+}$

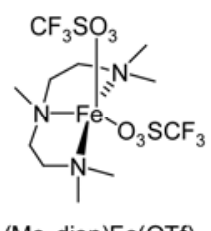

$\left(\mathrm{Me}_{5}\right.$ dien)Fe(OTf) 2

8

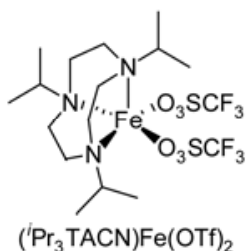

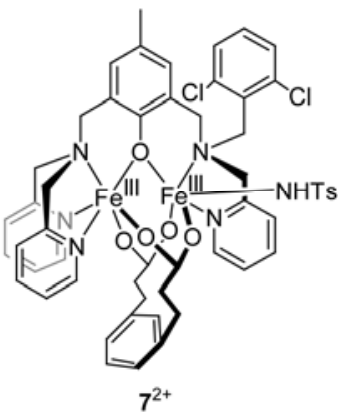

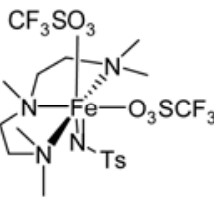

Imidoiron(IV) species

10
Scheme 12

indicated that a high-valent iron-imino species formed upon the oxidation of $7^{2+}$ by excess ArINTs might be the actual catalyst of aziridination.

Another type of non-heme iron complexes bearing the triamine ligand were reported by Halfen and co-workers [30], including $\left(\mathrm{Me}_{5} \mathrm{dien}\right) \mathrm{Fe}(\mathrm{OTf})_{2} 8$ and $\left({ }^{i} \operatorname{Pr}_{3} \mathrm{TACN}\right) \mathrm{Fe}-$ $(\mathrm{OTf})_{2} 9$ (Scheme 12). Although a small excess of alkene substrate (25 equiv versus PhINTs) was required, the reaction of styrene and PhINTs afforded the aziridine product in high yield (>95\%). Comparison studies of different iron(II) complexes on the catalytic reactivity revealed that a pair of cis labile coordination sites were crucial for effective catalysts. Further experimental and computational investigations on the mechanism [31] indicated that an imidoiron(IV) species 10, which is generated from the oxidation of the iron (II)-containing catalyst by PhINTs, would be a potential intermediate for the aziridination.

Although iron complexes containing tetra- or pentadentate nitrogen ligands were not good catalysts for styrene aziridination with PhINTs [30], six-coordinated iron complex 11 (Scheme 13) resulting from two terpyridine ligands was an effective catalyst for intermolecular and intramolecular aziridination of alkenes [32]. The intermolecular aziridination of aromatic and aliphatic alkenes with PhINTs or PhINNs afforded the aziridine products in good yields. Unsaturated sulfonamides were intramolecularly cyclized to give the bicyclic aziridines in high yields.

The iron-catalyzed aziridination reaction of alkenes with sulfonamides or PhINX (X=Ts, Ns, etc.) was also reported by Bolm and co-workers [33] in the presence of a simple iron salt $\mathrm{Fe}(\mathrm{OTf})_{2}$ (Scheme 14). The in situ generated iminoiodianes from the mixtures of the corresponding sulfonamide and $\mathrm{PhI}(\mathrm{OAc})_{2}$ made this reaction a variation of the aforementioned aziridination of PhINTs with alkenes [34].

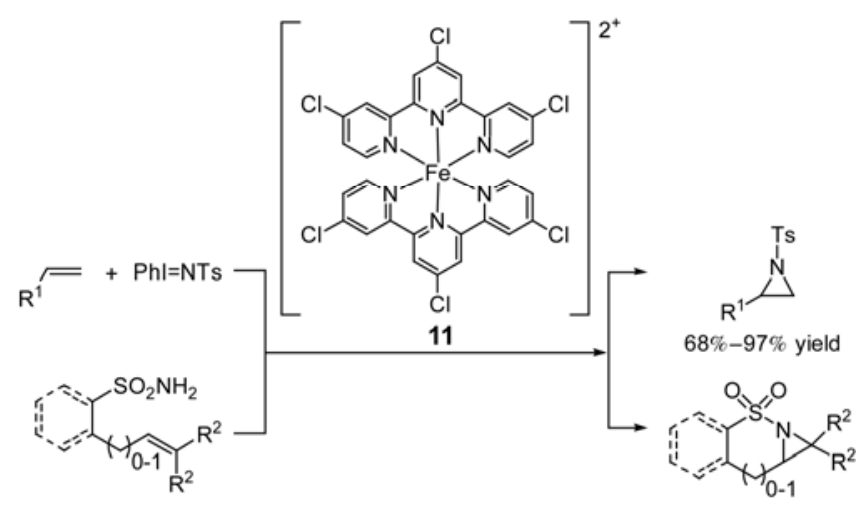

$86 \%-96 \%$ yield

Scheme 13

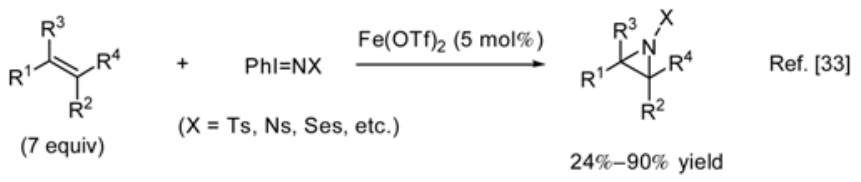$$
\text { (1 equiv) }
$$

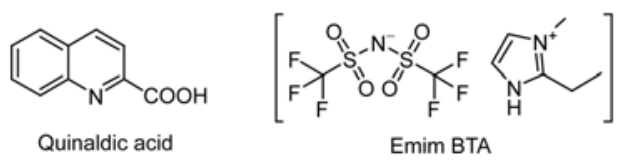

Scheme 14

It is noteworthy that the potential of asymmetric aziridination reaction was realized using $(S, S)$ - ${ }^{i} \mathrm{Pr}$-py-BOX as ligand with up to $40 \%$ ee. Further modification of this catalytic system by using ionic liquid emim BTA and quinaldic acid as additives allowed the reaction to be more practical and efficient [35].

The use of chloramine- $\mathrm{T}$ or bromamine- $\mathrm{T}$ as " $\mathrm{N}_{1}$ " source proved to be more environmentally benign compared with PhINTs. Gross and co-workers [36] disclosed an iron(III) corrole complex catalyzed aziridination of styrene derivatives with chloramines-T, whereas Zhang and co-workers [37] reported an aziridination of alkenes with bromamine-T in the presence of $\mathrm{Fe}(\mathrm{TPP}) \mathrm{Cl}$ (Scheme 15). Although only moderate yields were obtained in both cases, the main by-product $\mathrm{NaCl}$ and $\mathrm{NaBr}$ instead of $\mathrm{PhI}$ can be easily removed from the reaction system and thus allowing the procedure to be more practical.

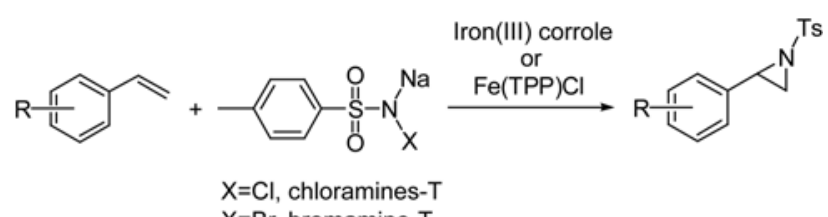

Scheme 15 
Because of the safety of the by-product (nitrogen gas) to the environment and higher atom-efficiency compared with PhINTs, organic azide has drawn great attention in organic synthesis and been applied in the aziridination reaction. Recently, Che and co-workers [38] reported the first example of iron-catalyzed aziridination of alkenes using aryl azides as nitrogen source under thermal and microwave-assisted conditions (Scheme 16). The aziridination of aryl alkenes can be accomplished by using $\mathrm{Fe}^{\mathrm{III}}\left(\mathrm{F}_{20}\right.$-tpp) $\mathrm{Cl}$ as catalyst with good yields under reflux, whereas slightly lower yields were obtained for aliphatic alkenes due to their lower reactivity. Under microwave irradiation conditions, the reaction time can be greatly reduced without significantly affecting the product yield and substrate conversion. However, the reported examples were mostly limited to the strongly electron-withdrawing aryl azides and/or styrene derivatives for alkenes.

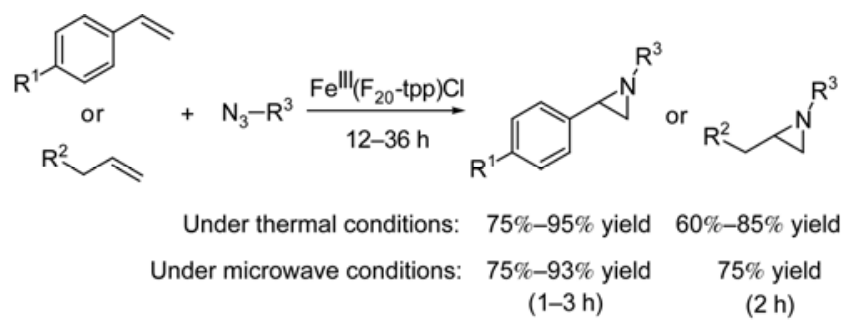

Scheme 16

More recently, Jenkins and co-workers [39] reported a tetracarbene iron(II) complex $\mathbf{1 2}$ catalyzed aziridination of aryl azides and a variety of substituted aliphatic alkenes (Scheme 17). Both electron-donating and -withdrawing aryl azides reacted effectively. Although low yields (20\%-39\%) and long reaction time $(144-160 \mathrm{~h})$ were found in most cases, substrates including tri- and tetrasubstituted aliphatic alkenes which were more challenging reagents than the styrene derivatives in previous studies have been successfully transformed into the corresponding aziridines. ESI-MS spectrum revealed that an $\mathrm{Fe}(\mathrm{IV})$ imide would be a potential intermediate. Importantly, since complex $\mathbf{1 2}$ is insoluble in

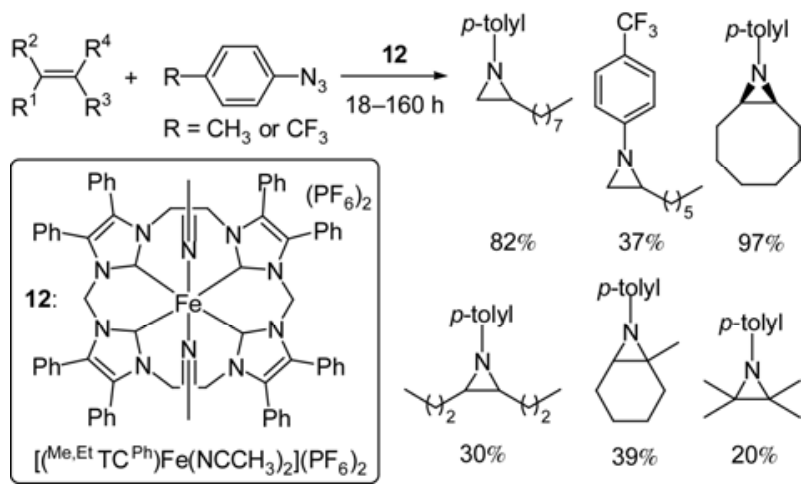

Scheme 17 the reaction mixture at room temperature, the catalyst can be easily separated and reused.

\subsection{Construction of four-membered rings}

The formation of four-membered ring systems can be accomplished by [2+2] cycloaddition under themal or photochemical conditions. Early in 1982, the [2+2] cycloaddition of alkenes and methyl tetrolate was reported by Rosenblum et al. [40] using a $\mathrm{CpFe}(\mathrm{CO})_{2}$ cation (complex 5 or 13) albeit with low yields (Scheme 18). The reaction outcome is strongly dependent on the structure of alkenes. For example, 1,2-disubstituted cyclic and aliphatic alkenes afforded cyclobutenes along with some 1,3-dienes, whereas 1,1-disubstituted or trisubstituted alkenes only gave the lactone salts.

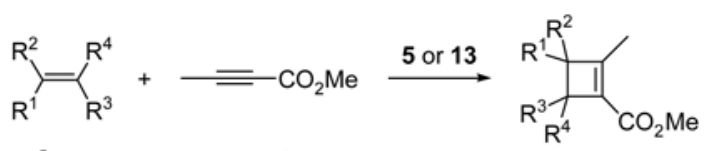

$\left[\left(\eta^{5}-\mathrm{C}_{5} \mathrm{H}_{5}\right) \mathrm{Fe}(\mathrm{CO})_{2}(\mathrm{THF})\right]^{+}\left[\mathrm{BF}_{4}\right]^{-}(\mathbf{5})$ :

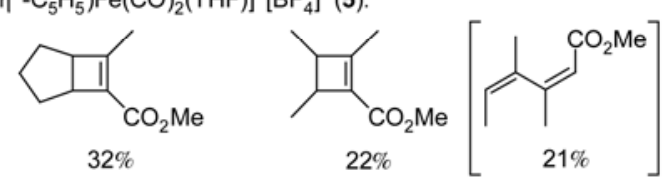

$\left[\left(\eta^{5}-\mathrm{C}_{5} \mathrm{H}_{5}\right) \mathrm{Fe}(\mathrm{CO})_{2} \text { (isobutylene) }\right]^{+}\left[\mathrm{BF}_{4}\right]^{-}(13)$ :

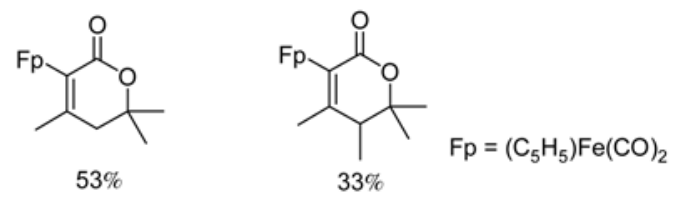

Scheme 18

In 2001, Itoh and co-workers [41] reported the [2+2] cyclodimerization of trans-anethole 14 using $\mathrm{Fe}\left(\mathrm{ClO}_{4}\right)_{3}$ and a BOX ligand as catalyst to afford anti-cyclobutane $\mathbf{1 5}$ in good yield (78\%, Scheme 19). Better result (92\%) was

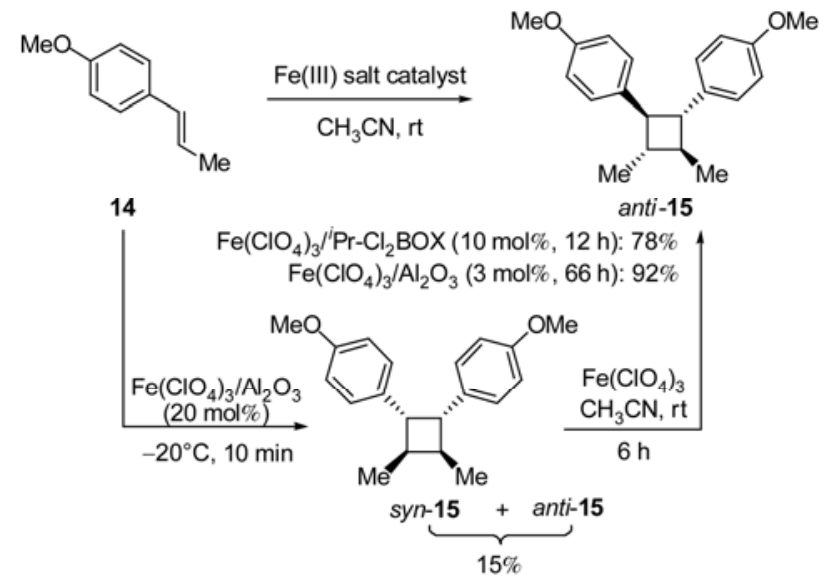

Scheme 19 
obtained when the $\mathrm{Fe}\left(\mathrm{ClO}_{4}\right)_{3}$ was supported by neutral $\mathrm{Al}_{2} \mathrm{O}_{3}$, although requiring longer reaction time. Importantly, when the reaction was carried out at lower temperature and stopped at 10 min, syn-15 and anti-15 were obtained in 15\% total yield. Further treatment of this mixture at room temperature for $6 \mathrm{~h}$ found that syn-15 was completely isomerized to anti-15, indicating that the cycloreversion of $s y n-\mathbf{1 5}$ took place and anti-15 was a more thermodynamically stable dimer.

This iron catalyst $\left(\mathrm{Fe}\left(\mathrm{ClO}_{4}\right)_{3} / \mathrm{Al}_{2} \mathrm{O}_{3}\right)$ was subsequently applied to the cycloaddition of styrene derivatives with quinine by the same authors in excellent yields and trans selectivity (Scheme 20) [42]. Remarkable acceleration was observed when ionic liquid [bmin] $\mathrm{PF}_{6}$ was used as solvent, which required only $10 \mathrm{~min}$ to furnish the product. The reaction was proposed to be caused by one-electron oxidation in the presence of iron(III) cation and followed by the rearrangement of the cycloadduct from alkene and quinine to afford the desired products.

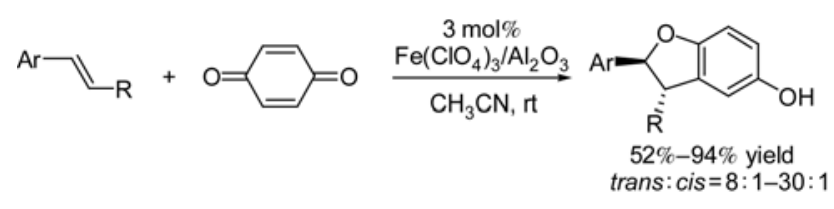

Scheme 20

An iron-catalyzed intramolecular [2+2] cycloaddition of $\alpha, \omega$-dienes was reported by Chirik and co-workers [43]. In the presence of an iron bis(nitrogen) complex bearing a bis(imino)pyridine ligand, $\left({ }^{i \mathrm{Pr}} \mathrm{PDI}\right) \mathrm{Fe}\left(\mathrm{N}_{2}\right)_{2}\left(\mathbf{1 6}-\left(\mathrm{N}_{2}\right)_{2}\right)$, the cycloaddition of unactivated 1,6-heptadienes to [0.2.3]bicycloheptane afforded only the cis products with more than 90\% conversion (Scheme 21). Amine and ester functional groups on the substrates were well tolerated with the catalyst, except those with secondary amine or $\mathrm{SiMe}_{2}$ groups. Mechanism studies revealed that $\mathrm{Fe}(\mathrm{II})$ rather than $\mathrm{Fe}(0)$ acted as the active species, and the redox activity of the ${ }^{i}$ PrPDI ligand preserved the ferrous oxidation state throughout the catalytic cycle.

Very recently, they reported a more challenging iron

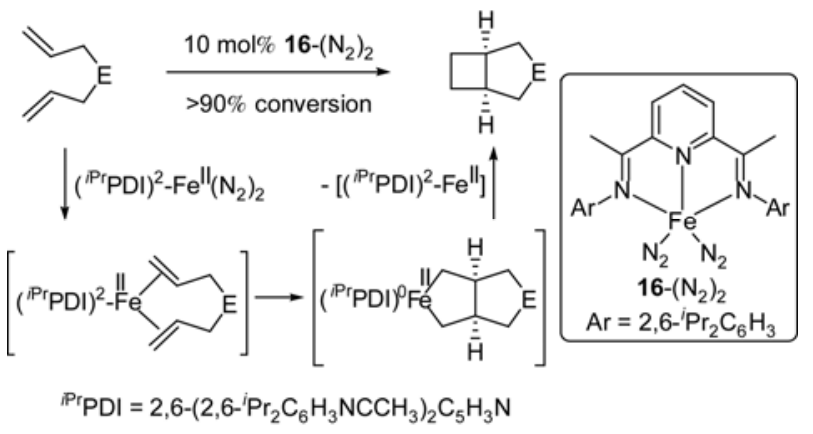

Scheme 21 catalyzed intermolecular [2+2] cycloaddition reaction of ethylene and butadiene to furnish vinylcyclobutane in $95 \%$ yield [44]. However, when a methyl group was introduced into the diene substrate, 5-methylhexa-1,4-diene was obtained as the main product (95\% yield). Deuterium labeling experiments revealed that intermolecular [2+2] cycloaddition and 1,4-addition reaction were carried out in the presence of different substrates, respectively (Scheme 22). Importantly, isolation of the iron metallocycle intermediate 18 as well as the stoichiometric experiments of $\mathbf{1 8}$ with alkenes or $\mathrm{CO}$ disclosed the reaction mechanism. The reaction was initialized through the displacement of the dinitrogen ligands by butadiene to form iron metallocycle intermediate $\mathbf{1 7}$, followed by the oxidative coupling of ethylene to generate 18. Butadiene-induced reductive elimination furnished the vinylcyclobutane and regenarated the iron butadiene compound 17. When isoprene was used as substrate, $\beta$-hydrogen elimination took place and subsequently $\mathrm{C}-\mathrm{H}$ reductive elimination resulted in the 1,4-addition product.
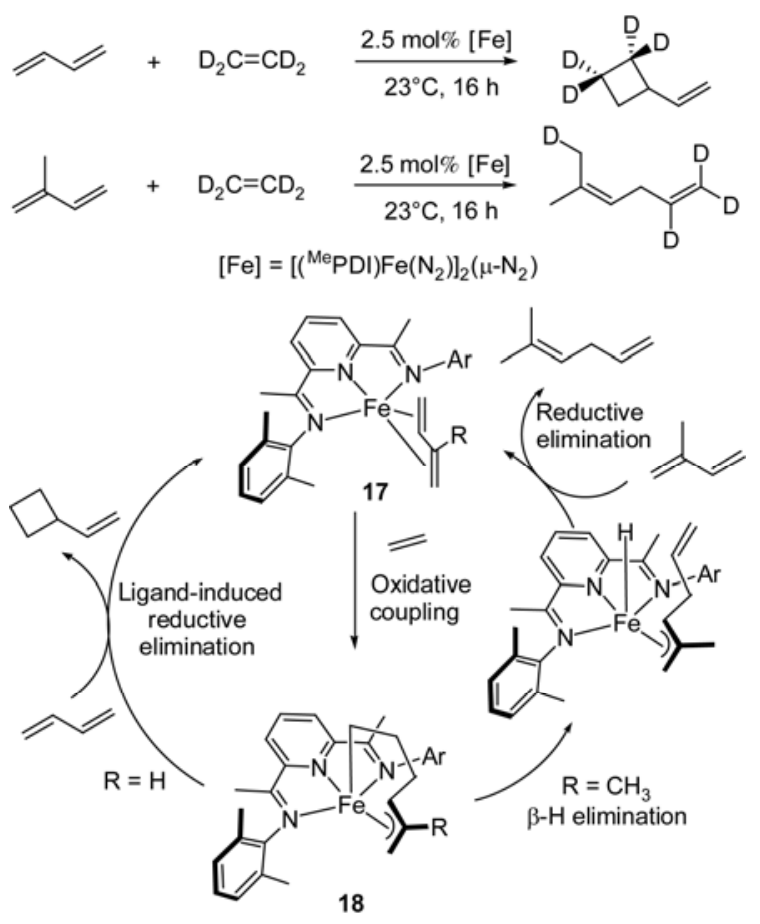

Scheme 22

\subsection{Construction of five-membered rings}

The generation of five-membered ring compounds can be achieved by $[2+2+1],[4+1]$ or $[3+2]$ cycloaddition reactions. Since there are no further developments on the iron catalyzed [4+1] cycloaddition reactions after the work by Eaton and co-workers [45-49], this part will not be discussed here.

(1) $[2+2+1]$ cycloaddition. Stoichiometric $[2+2+1]$ cycloaddition of diynes and $\mathrm{Fe}(\mathrm{CO})_{5}$ was reported by Knölker et al. [50,51]. In the presence of 2 equiv $\mathrm{Fe}(\mathrm{CO})_{5}$, the $[2+2+1]$ cycloaddition of 1,8-dialkynylnaphthalene $\mathbf{1 9}$ or 
diyne 21 with carbon monoxide afforded the tricarbonyliron complex $\mathbf{2 0}$ or $\mathbf{2 2}$ in $90 \%$ and $99 \%$ yield (Scheme 23), respectively. Further transformation of these two iron complexes provided corannulene and norketoyobyrine in good yields. This method has demonstrated that the iron-mediated $[2+2+1]$ cycloaddition of diynes can be applied to the construction of polycyclic frameworks and the total synthesis of biologically active alkaloids as the key step.

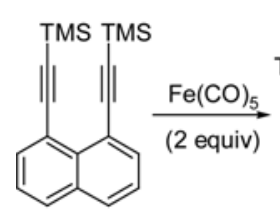

19

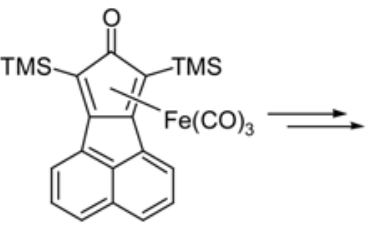

$20,90 \%$

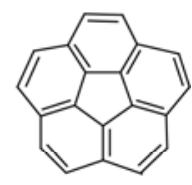

Corannulene

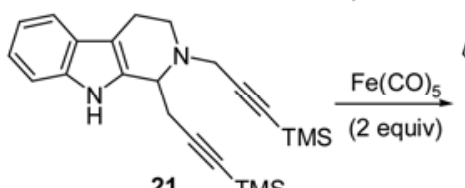

21
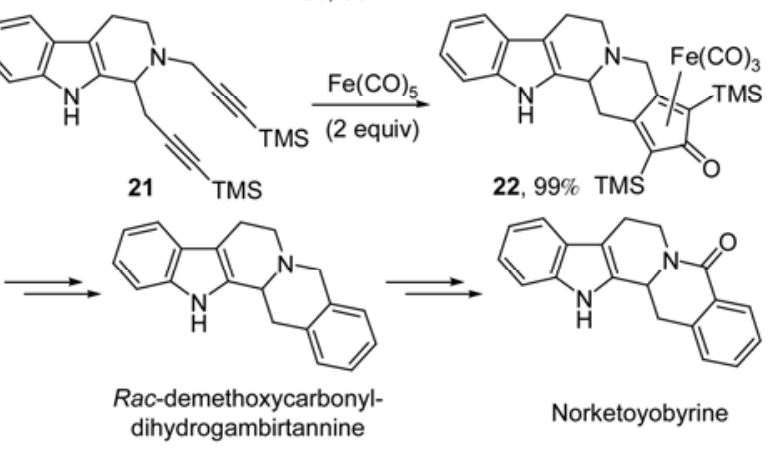

Norketoyobyrine

Scheme 23

A hetero-Pauson-Khand-type $[2+2+1]$ cycloaddition reaction of ketimines, carbon monoxide and ethylene under catalytic amount of $\mathrm{Fe}_{2}(\mathrm{CO})_{9}$ was reported by Imhof and co-workers [52]. The reaction exclusively took place at the imine functional group adjacent to the oxazine oxygen atom (Scheme 24), however, only 55\% of 1,4-diazabutadiene $\mathbf{2 3}$ was converted to spirolactam $\mathbf{2 4}$ and the reaction scope was rather limited. In addition, mixed compounds or no reaction was observed in the absence of carbon monoxide or ethylene (Scheme 24), respectively, which indicated that the insertion of ethylene would be the first reaction step. The reaction of an imine instead of a 1,4-diazabutadiene under the same conditions only proceeded with lower selectivity. This result revealed that the ketimine functionality acted as a bidentate ligand and subtle substituent effects were responsible

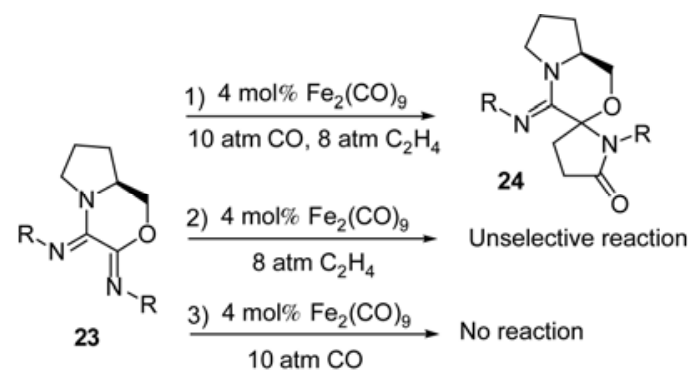

Scheme 24

for the regioselectivity, as also suggested by the theoretical studies [53].

(2) $[3+2]$ cycloaddition. The $[3+2]$ cycloaddition reaction of $\eta^{1}$-allyl iron complexes with unsaturated electrophilic reagents provided an alternative approach to the ironsubstituted cyclic compounds. After removal of the iron moiety, five-membered rings were obtained. Turos and coworkers [54] reported a [3+2] cycloaddition reaction of $N$ tosylimines with allyl(cyclopentadienyl)iron(II) dicarbonyl complexes in the presence of $15 \mathrm{~mol} \% \mathrm{ZnCl}_{2}$. Subsequent treatment with a methanolic solution of ceric ammonium nitrate under an atmosphere of $\mathrm{CO}$ afforded the pyrrolidine methyl esters as a mixture of diastereomers (Scheme 25).
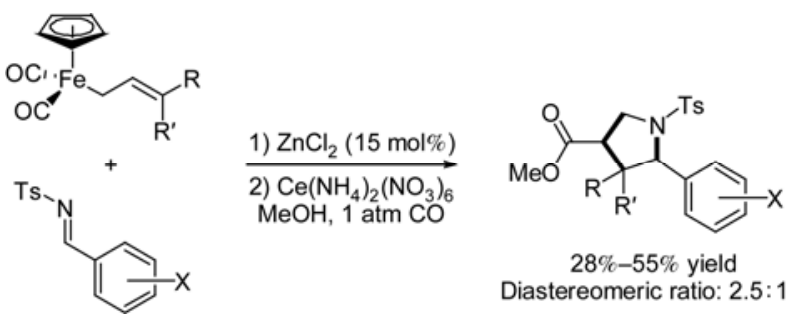

Scheme 25

Similar reactions between the iron(II) complex and iminium salts of aldehydes and ketones were demonstrated by Ipaktschi and co-workers [55] with good to excellent yields. Reactions of allyl(cyclopentadienyl)iron(II) dicarbonyl complexe with in situ generated iminium salts from aldehydes and a secondary amine also gave the iron complexes in excellent yields (Scheme 26). Further demetalation of these compounds under $\mathrm{CuCl}_{2}$ yielded the metal-free pyrrolidine methyl esters.

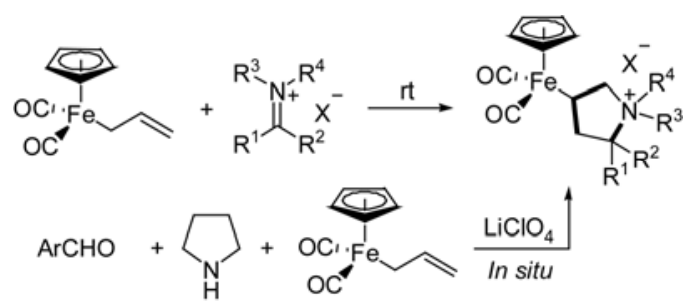

Scheme 26

(1-Indenyl)iron compounds, the analogue of allyliron complexes, were also capable of participating in [3+2] cycloadditions [56]. Reactions of (1-indenyl)Fp with maleic anhydride or tetracyanoethylene gave the corresponding cycloadducts in 51\% and 93\% yield (Scheme 27), respectively. Other substrates such as dimethyl fumarate, dimethyl acetylenedicarboxylate and diethyl azodicarboxylate failed to react.

Along with the aforementioned iron complexes, simple 


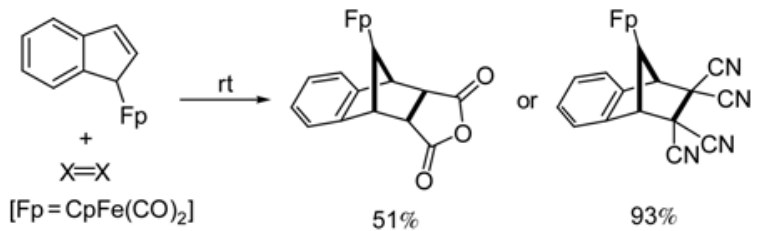

Scheme 27

iron salt $\mathrm{FeCl}_{3}$ also acted as a good catalyst for the construction of pyrroline rings from $N$-tosyl aziridines and terminal arylalkynes, as reported by Wang and co-workers [57] (Scheme 28). Transformation of 2-pyrrolines into $\gamma$-amino ketones was achieved by a one-pot protocol of aziridines and arylalkynes under mild conditions. Additional experiments revealed that strong electron-deficient or unactivated aziridines as well as alkyl alkynes were not good substrates for this reaction, and resulted in completely no reaction.

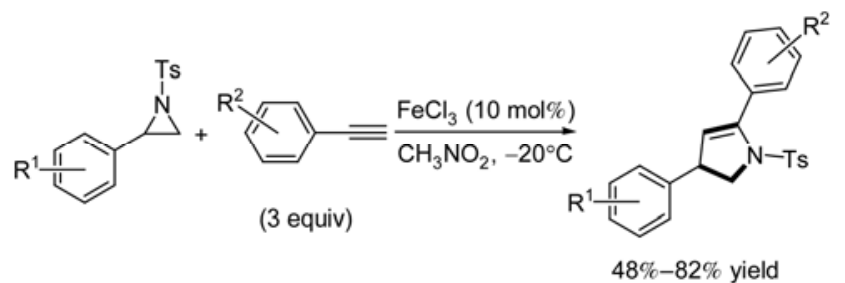

Scheme 28

The asymmetric [3+2] cycloaddition reactions of nitrones and enals were described by Kündig and co-workers [58] using a chiral iron Lewis acid $(R, R)-\mathbf{2 5}$ as the catalyst (Scheme 29 ). Good to excellent yields and high enantioselectivity (up to $96 \%$ ) were obtained in the reaction of pyrrolidine $N$-oxide and methacrolein. However, longer reaction times were required $(>120 \mathrm{~h})$ when diaryl nitrones were subjected to this reaction, and a mixture of regioisomers in ratios varying
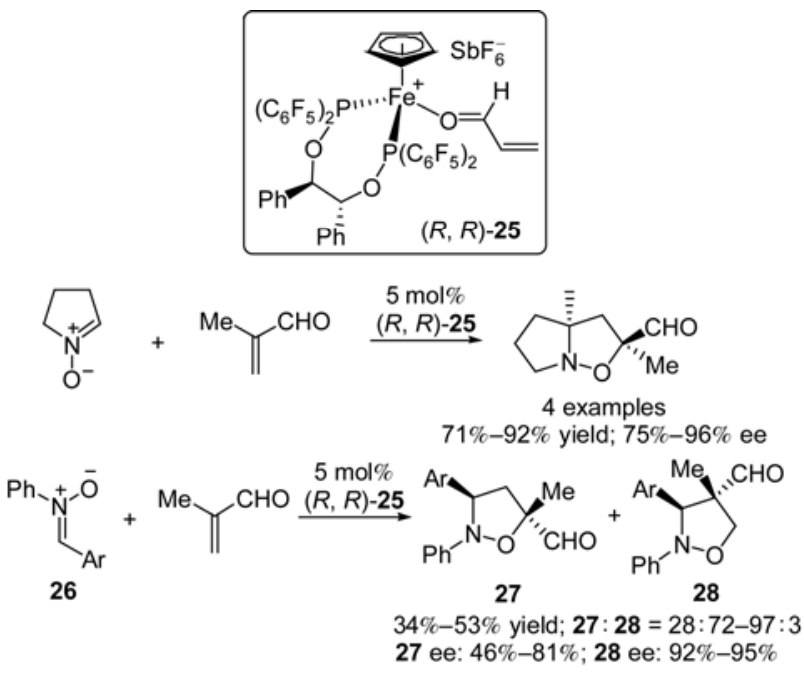

Scheme 29 from 28:72 to $93: 3$ was observed [59]. The isoxazolidine products $\mathbf{2 7}$ and $\mathbf{2 8}$ were generated from the asymmetric $[3+2]$ cycloaddition between diaryl nitrones and methacrolein in moderate yields (34\%-53\%), high enantioselectivity (up to 95\%) and complete endo selectivity. Experimental and computational studies suggested that the regioselectivity was dependent on the electronic properties of the nitrone.

Recently, Wang and co-workers [60] reported the first example of $\mathrm{Fe}(\mathrm{II}) / \mathrm{N}, \mathrm{O}$-ligand (29) catalyzed asymmetric [3+2] cycloaddition reaction of azomethine ylides with alkenes. In the presence of $10 \mathrm{~mol} \% \mathrm{FeCl}_{2}$ and diaryl prolinol, the reaction of azomethine ylides with electron-deficient alkenes underwent smoothly to afford the endo-adducts $\mathbf{3 0}$ in moderate to good yields and enantioselectivities (up to $78 \%$, Scheme 30).

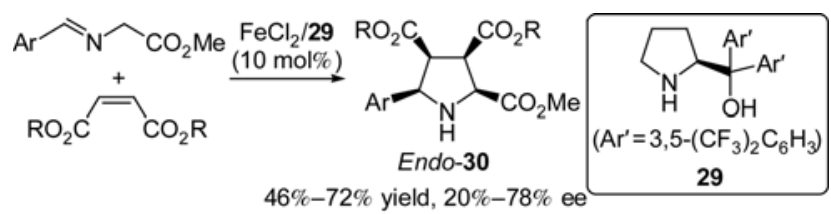

Scheme 30

\subsection{Construction of six-membered rings}

(1) $[2+2+2]$ cycloaddition. Transition metal-catalyzed $[2+$ $2+2]$ cycloaddition of unsaturated compounds, such as alkynes, nitriles, alkenes, imines and isocyanates, is the most atom-economical protocol for the synthesis of six-membered ring compounds [61-74]. Although various types of catalysts and substrates have been subjected to the inter- and intramolecular reactions, the development of iron-catalyzed $[2+2+2]$ cycloadditions was very slow and the substrates were mainly focused on the alkynes and nitriles. In particular, the chemoselectivity as well as the regioselectivity remains a crucial problem in these reactions.

An iron sandwish complex was applied to the intermolecular cyclotrimerization reaction of terminal or internal alkynes by Pertici and co-workers [75]. In the presence of $0.6 \mathrm{~mol} \% \mathrm{Fe}\left(\eta^{6}-\mathrm{CHT}\right)\left(\eta^{4}-\mathrm{COD}\right) \quad(\mathrm{CHT}=$ cyclohepta-1,3,5triene; $\mathrm{COD}=$ cycloocta-1,5-diene), polysubstituted benzenes were obtained with good to excellent yields. However, for most terminal alkynes, a mixture of two regioisomers was produced in a ratio of ca. $1: 1$. Better selectivity $(\mathbf{3 1}: \mathbf{3 2}=$ $95: 5)$ was realized when large difference between two substituent groups on the alkyne molecular (e.g. H and TMS, Scheme 31).

Recently, a highly regioselective cyclotrimerization of terminal alkynes catalyzed by $\mathrm{Fe}(\mathrm{II})$ complexes bearing $N, N, N$-ligands was reported by Yang and co-workers [76]. The in situ generated low valent iron catalyst from the iron complex 33, $\mathrm{Zn}$ and $\mathrm{ZnI}_{2}$ in acetonitrile was tested with various terminal alkynes (Scheme 32). 1,2,4-Trisubstituted benzenes 34 were found to be the major products for aryl 


$$
\mathrm{R}^{1}=\mathrm{R}^{2} \frac{\mathrm{Fe}\left(\eta^{6}-\mathrm{CHT}\right)\left(\eta^{4}-\mathrm{COD}\right)}{\mathrm{rt}, \mathrm{THF}} \mathrm{Ror}_{\mathrm{R}^{1}=\mathrm{TMS}, \mathrm{R}^{2}=\mathrm{H}: 31: 32=95: 5}^{31}
$$

Scheme 31

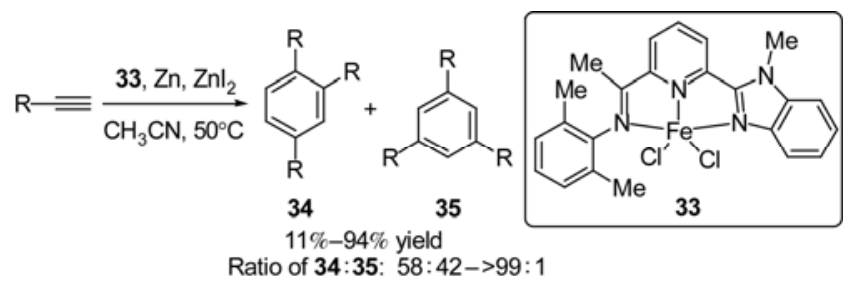

Scheme 32

alkynes in good to excellent yields, whereas the regioselectivity for alkyl alkynes is only moderate $(\mathbf{3 4 : 3 5}=58: 42-$ $62: 38)$. It is worth mentioning that no pyridine byproducts were observed from the cycloaddition of two alkynes and a nitrile even using $\mathrm{CH}_{3} \mathrm{CN}$ as the solvent.

The regioselective problem can be avoided by utilizing the intramolecular cyclotrimerization of triynes, which was accomplished by Okamoto and co-workers [77,78]. The triynes could be effectively cyclotrimerized to annulated benzenes by treatment with a catalytic amount of $\mathrm{FeCl}_{3}, \mathrm{Zn}$ power and either $N$-heterocyclic carbene IPr or diimine ligand 36 with up to $98 \%$ yield (Scheme 33). The using of 2-(iminomethyl)pyridine $\mathbf{3 7}$ as the ligand instead of IPr or 36 could tolerate trace amount of water, thus allowing to use the hydrate form $\mathrm{FeCl}_{3} \cdot 6 \mathrm{H}_{2} \mathrm{O}$ and make this catalytic system more practical.

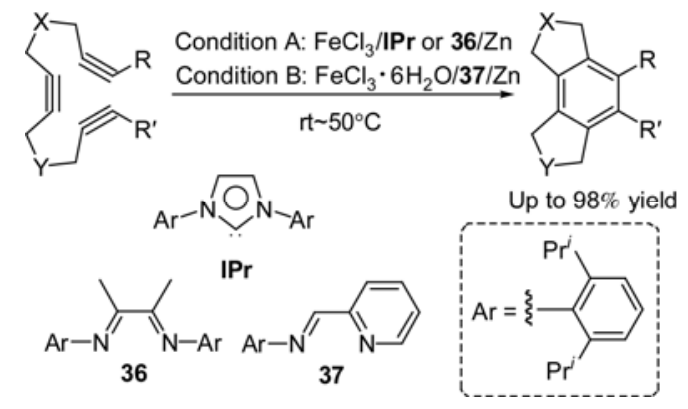

Scheme 33

Low valent iron olefin complexes with the oxidation state 0 and +1 were also effective catalysts for the cyclotrimerization of triynes. In the presence of $\mathrm{Fe}(0)$ complex 38 or $\mathrm{Fe}(+1)$ complex 39, triyne was smoothly converted into the annulated benzene, although a higher catalyst loading and a longer reaction time were required for catalyst 39
(Scheme 34) [79]. Similarly, diyne also dimerized cleanly in $70 \%$ yield. Stoichiometric reaction of 39 with 1,2-diphenylacetylene afforded the 17-electron $\mathrm{Fe}(+1)$ cyclobutadiene complex 41, which indicated the formation of ferracycle intermediate $\mathbf{4 0}$.

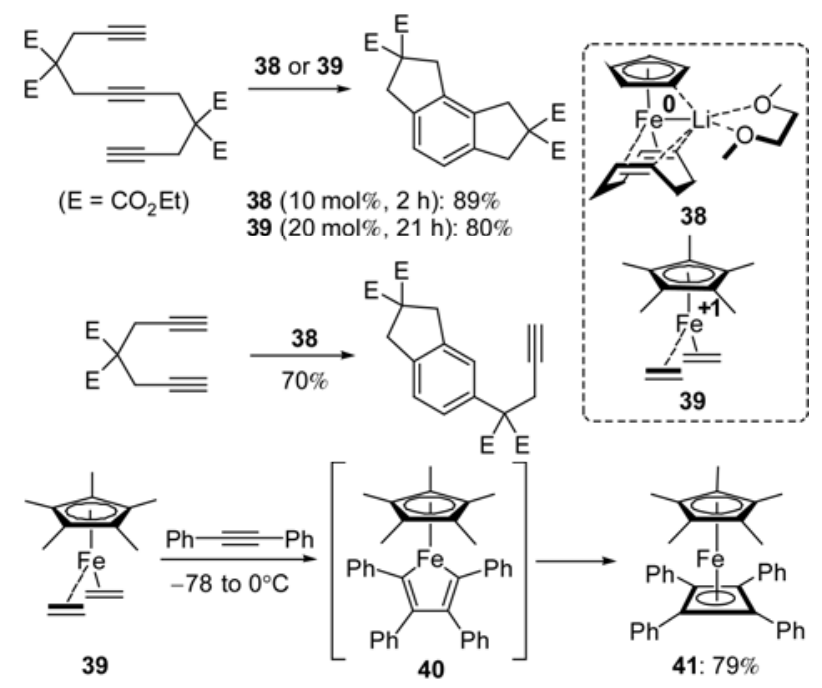

Scheme 34

The increased oxidation number of the iron center by two in the ferracycle intermediate favored subsequent coordination of a nitrile rather than an alkyne, thus allowing the formation of pyridine derivatives. Zenneck and co-workers [80] developed an $\mathrm{Fe}(0)$ complex 42 catalyzed $[2+2+2]$ cycloaddition of two molecules of alkynes and nitriles (Scheme 35), however, this approach gave low chemoselectivity (benezenes were the main products) and had a complicated procedure for catalyst preparation. A stoichiometric reaction between an $\mathrm{Fe}(+1)$ complex and alkynes was report by Guerchais and co-workers [81] with high chemoselectivity (Scheme 36). The nature of the solvent has a great effect on the reaction product, for instance, the using of $\mathrm{CH}_{3} \mathrm{CN}$ as solvent gave 2,3,6-trisubstitued pyridine $\mathbf{4 4}$ in $73 \%$ yield whereas only $\pi$-pyridine iron complexes were obtained in the presence of $\mathrm{CH}_{2} \mathrm{Cl}_{2}$ instead of $\mathrm{CH}_{3} \mathrm{CN}$.

Recently, Wang and co-workers [82] reported an ironcatalyzed $[2+2+2]$ cycloaddition of diynes and unactivated

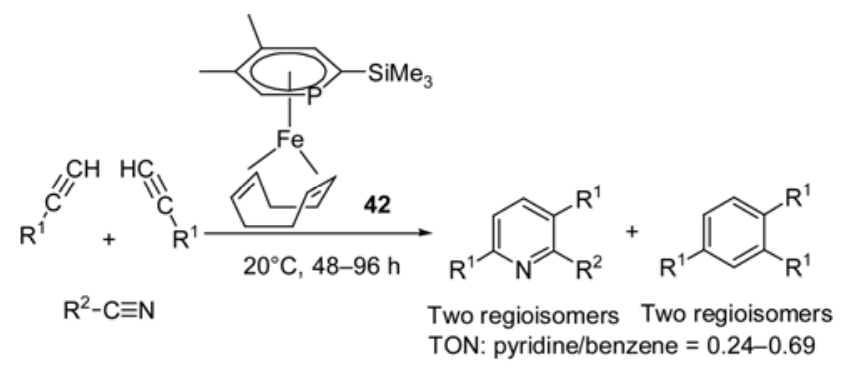

Scheme 35 


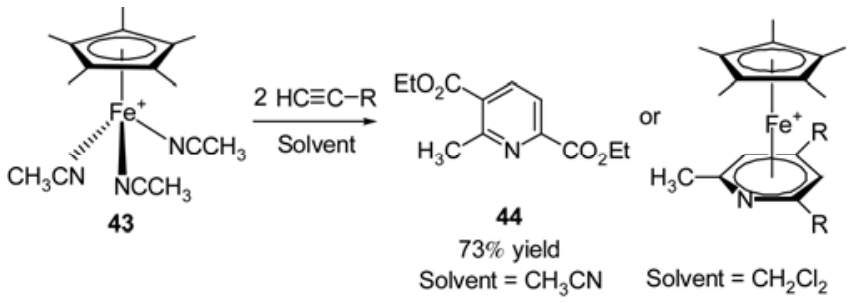

Scheme 36

nitriles at room temperature to produce pyridine compounds in good to excellent yields (Scheme 37). The catalyst is generated in situ from an inorganic iron salt and a diphosphine ligand with zinc dust as reductant, and exhibited high reactivity and regioselectivity. The intermolecular cycloaddition of monoalkynes exclusively afforded the 1,2,4-trisubstituted benzene $\mathbf{4 6}$ in $55 \%$ yield, whereas the intermolecular cyclocotrimerization of phenylacetylene with 5 equiv $\mathrm{CH}_{3} \mathrm{CN}$ gave two pyridines isomers 47 and 48 in $60 \%$ and $6 \%$ yield, respectively (Scheme 38 ). The competition experiment between acetonitrile and 3 equiv phenylacetylenes only provided a small amount of pyridine product 47 , and no desired product $\mathbf{4 6}$ was formed, which indicated that the

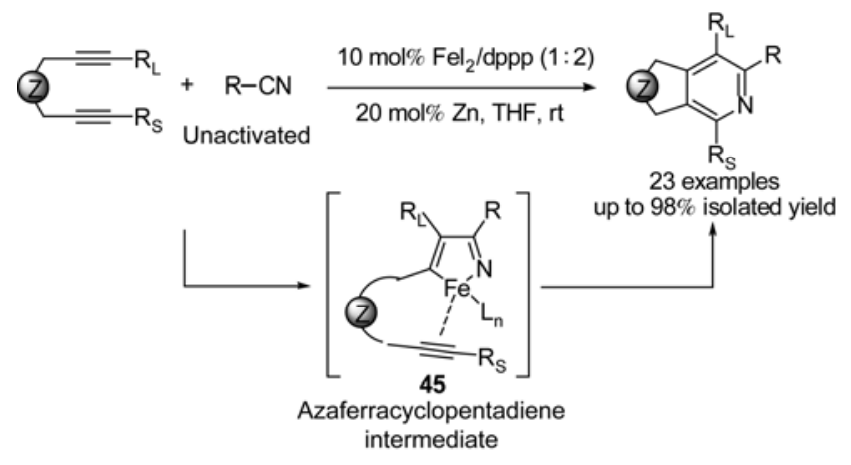

Scheme 37

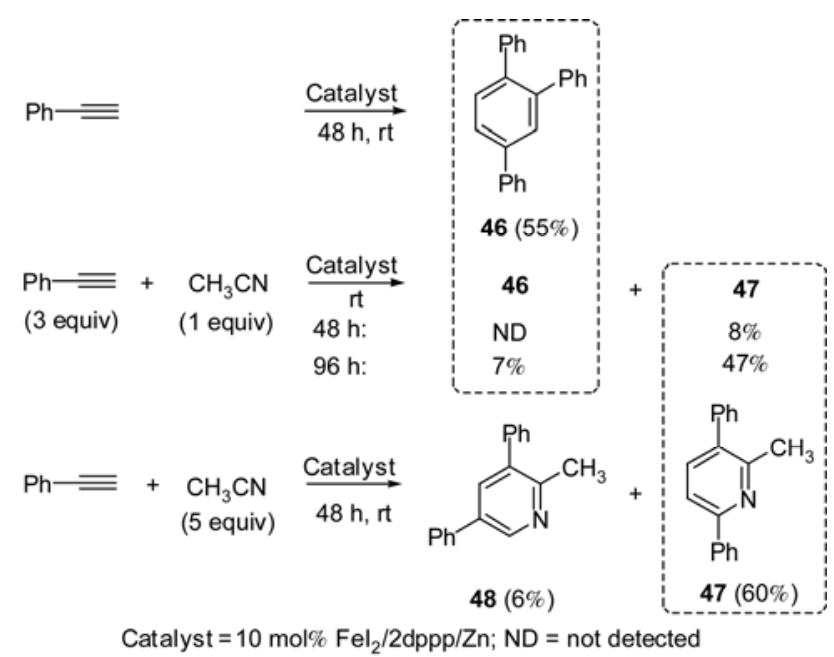

Scheme 38 formation of the ferracyclopentadiene intermediate was strongly inhibited in the presence of nitrile and the transformation would take place via an azaferracyclopentadiene intermediate 45 (Scheme 37). However, the combination of alkynenitrile with alkyne in a 1:1 ratio proved unsuccessful, only leading to the complete intermolecular cycloadduct of alkynenitrile and two alkynes.

Almost at the same time, the iron-catalyzed [2+2+2] cycloaddition of alkynenitriles and alkynes was reported by Louie and co-workers [83] using a similar methodology. In the presence of $\mathrm{Fe}(\mathrm{OAc})_{2}$, bis(imino)pyridine ligand 49 and zinc power, alkynenitriles and alkynes readily cyclized to form a variety of substituted pyridines in good yields although slightly higher reaction temperature was required (Scheme 39). The cycloaddition reactions of unsymmetrical alkynes (aryl-alkyl alkynes and alkyl-alkyl alkynes) with alkynenitrile afforded regioisomers $\mathbf{5 0}$ and $\mathbf{5 1}$ in ratios ranging from $0: 1$ to $4: 1$ (Scheme 40). Interestingly, a single regioisomer was obtained in the reaction of a sterically hindered alkyne $\left(\mathrm{R}^{1}=\mathrm{Me}, \mathrm{R}^{2}={ }^{t} \mathrm{Bu}\right)$ with the ${ }^{t} \mathrm{Bu}$-group proximal to the nitrogen of pyridine. Specifically, the catalytic system was also effective in the all-intermolecular cycloaddition to give the tricyclic product in $74 \%$ yield.

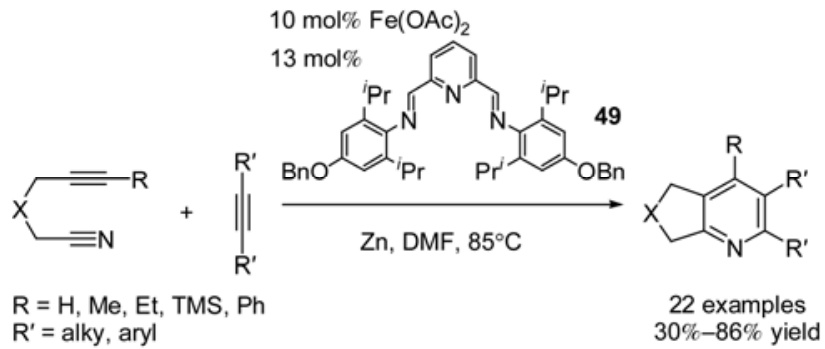

Scheme 39
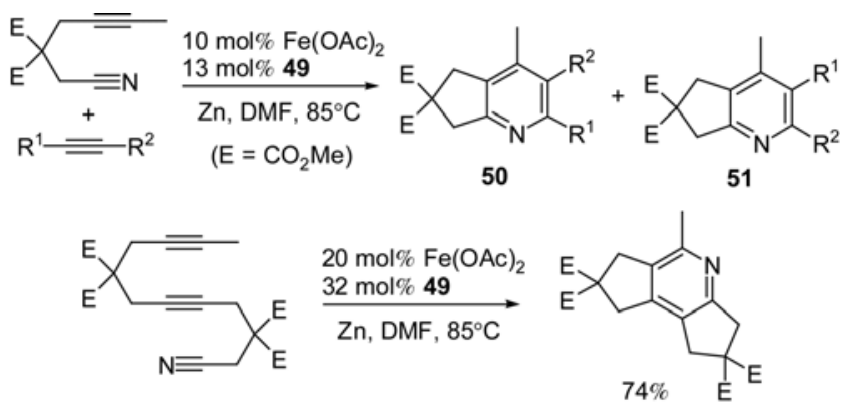

Scheme 40

(2) [4+2] cycloaddition. Another approach for the generation of six membered rings is the [4+2] cycloaddition reaction, which mainly focuses on the Diel-Alder (DA) reaction of a diene and a dienophile. Three types of the iron-catalyzed DA reactions including normal $\mathrm{HOMO}_{\text {diene-controlled, neu- }}$ tral and inverse $\mathrm{HOMO}_{\text {diene-controlled reactions (Scheme 41) }}$ have been recently summarized by Hilt et al. [15]. Interestingly, 


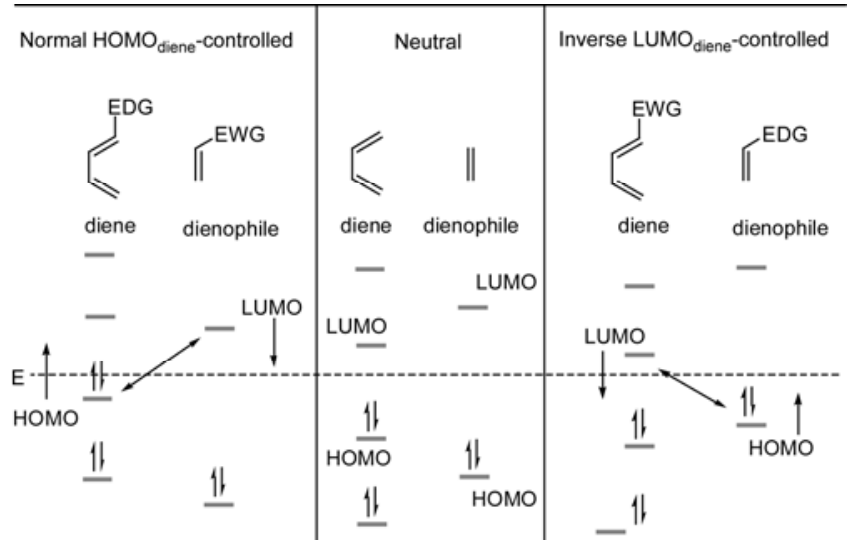

Scheme 41

these reactions can be promoted effectively by iron catalysts in different oxidation states, for instance, the dienophiles with electron-withdrawing groups (EWG) can coordinate to the iron catalysts in high oxidation states and lower the LUMO energy, whereas the low valent iron complexes are able to coordinate the neutral starting materials and transform the reactants into corresponding cycloadducts. However, only a few examples on the iron-catalyzed DA reactions have been reported recently and mostly in an asymmetric manner.

Application of chiral iron catalysts to the [4+2] cycloaddition allowed the generation of chiral products and induction of stereoselectivity. Typical substrates used in the DA reactions are cyclopentadiene, acrolein, acrylate and acrylamide derivatives. Early in 1991, Corey et al. [84] reported the first asymmetric reaction between 3-acryloyl-1,3-oxazolidin-2-one and cyclopentadiene utilizing an iron complexes generated in situ from $\mathrm{FeI}_{3}, \mathrm{I}_{2}$ and chiral ligand 52 (Scheme 42). Endo product was predominantly obtained in $95 \%$ yield, $92 \%$ selectivity and $82 \%$ ee. Interestingly, when fluxional additives were added into a similar catalyst system consisted of $\mathrm{Fe}\left(\mathrm{ClO}_{4}\right)_{2}$ and ligand 52, a large increase in ee value was observed [85]. Better results (up to $98 \%$ ee) were

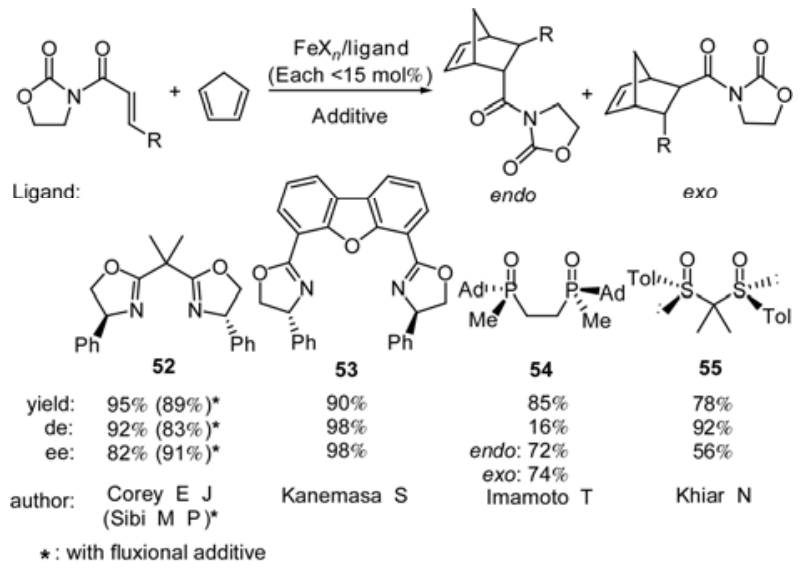

Scheme 42 achieved by Kanemasa and co-workers [86,87] using an iron aqua complex of chiral bisoxazole ligand 53, water, alcohols, amines and acids were well tolerated. Other bidentate ligands such as phosphorus dioxide ligand 54 [88] and disulfoxide ligand 55 [89] were also developed but with lower efficiency.

On the other hand, tridentate ligand pybox was employed in the catalytic enantioselective DA reaction of polysubstituted silyl enol ethers by Shibasaki and co-workers [90]. High enantioselectivity (up to $92 \%$ ee) was obtained using a catalyst generated from $\mathrm{FeBr}_{3}$ and $(R, R)$-aryl-pybox 56 (Scheme 43). Application of this methodology to the enantioselective synthesis of hyperforin, garsubellin A or enthyperforin was accomplished by the same authors [91,92].

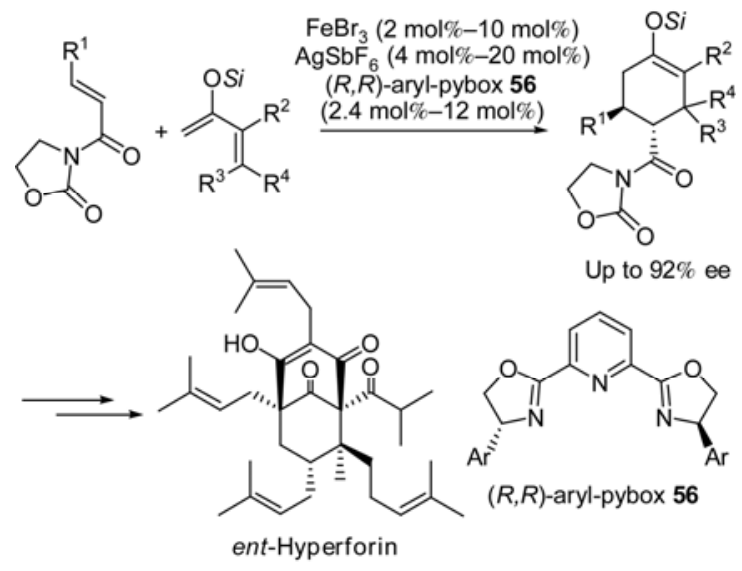

Scheme 43

In addition to these ligands, iron cyclopentadienly catalyst $(R, R)-25$ and its derivatives bearing chiral phosphorus ligands were applied to the asymmetric DA reaction of $\alpha, \beta$ enals and dienes by Kündig and co-workers [93-95] (Scheme 44). Good yields, high diastereoselectivities (mainly exo products) and excellent enantioselectivities were obtained.

The [4+2] cycloaddition of 1,3-butadiene with ethyne or propyne mediated by bare $\mathrm{Fe}^{+}$in the gas phase was reported by Jacobson and co-workers [96]. $\mathrm{Fe}^{+}$was generated by laser desorption/ionization from a high-purity iron foil and formed $\mathrm{Fe}\left(1,4-\right.$ cyclohexadiene $^{+}$from ethyne. Subsequent
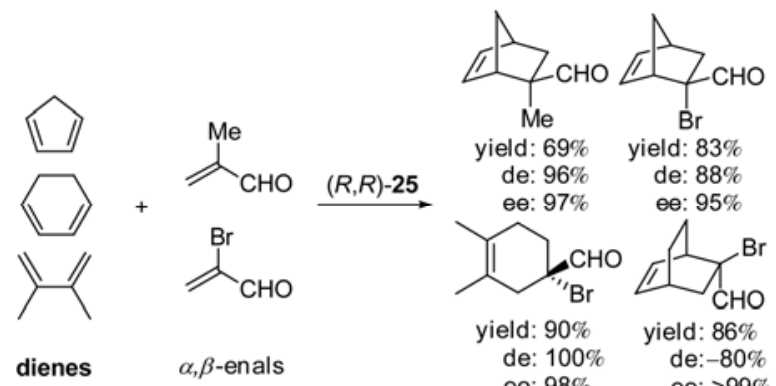

Scheme 44 
dehydrogenation produced the corresponding $\mathrm{Fe}(\text { benzene })^{+}$ complex. The intramolecular [4+2] cycloaddition of dieneynes catalyzed by $\mathrm{Fe}(0)$ complex $\mathbf{3 8}$ was described by Fürstner et al. [79] albeit with only moderate yields (Scheme 45).
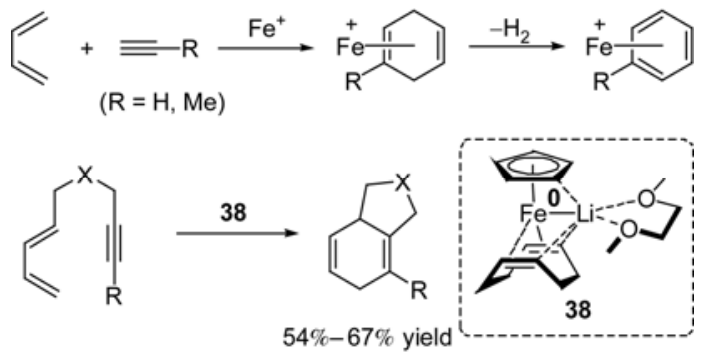

Scheme 45

Recently, stoichiometric cycloaddition reactions of alkynes or 1-haloalkynes with vinylketeneiron(0) complexes affording the catechol derivatives were described by Schnatter and co-workers [97,98] (Scheme 46). However, two regioisomers with moderate yields were generally obtained and the reaction with several alkyl, silyl and aryl alkynes produced alkyne trimers as the major products. The steric hindrance rather than the electronic factors of the alkynes accounts for the regioselectivity.

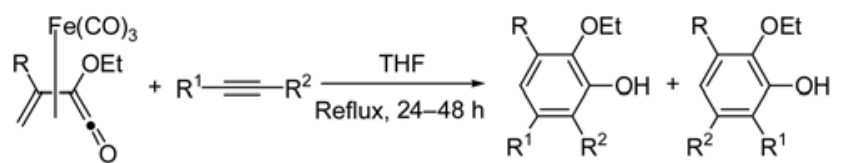

Scheme 46

\subsection{Construction of seven-membered rings}

Compared with other ring construction methods, approaches to seven-membered rings are not so abundant. The [5+2] cycloaddition reactions present a great potential to synthesize seven-membered ring systems [99]. However, only a single report by Fürstner and co-workers [79] on the iron catalyzed [5+2] cycloaddition has appeared so far. The intramolecular reaction of vinylcyclopropane and alkyne proceeded smoothly in the presence of $\mathrm{Fe}(0)$ complex $\mathbf{3 8}$ or $\mathbf{5 7}$ (Scheme 47), providing the cycloadducts $\mathbf{5 8}$ and $\mathbf{5 9}$ in good to excellent yields combined with moderate to good diastereoselectivities. In accordance with the previous results (Schemes 34 and 45), the COD-containing complex 38 proved more efficient than other $\mathrm{Fe}(0)$ complexes.

\section{Conclusions}

The rapid generation of molecular in a relatively easy manner has made the cycloaddition reaction a powerful tool in the
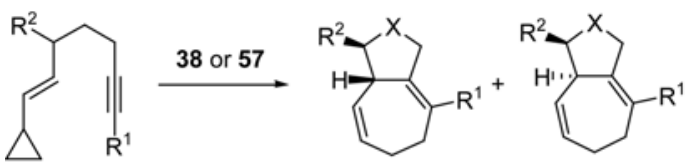

58 (major) 59 (minor)

$54 \%-99 \%$ yield

$58: 59=2.3: 1-15: 1$
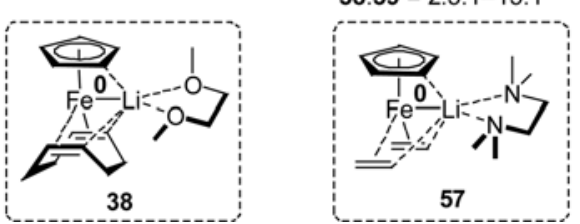

Scheme 47

synthesis of three-, four-, five-, six- and seven-membered ring compounds. Clearly, iron catalysts are becoming a much more interesting and viable choice for this purpose. In this review, we have presented a number of promising results in the iron catalyzed cycloaddition reactions during the past few years. Notable improvements have been made on the exploration of novel iron catalysts, including iron Lewis acids as well as preformed or in situ generated low valent iron catalysts. Importantly, chiral iron complexes or iron catalysts with chiral ligands have been successfully applied to the asymmetric cycloadditions.

Despite the gratifying achievements obtained in the iron catalyzed cycloaddition reactions, this area is still far from the mature state and is full of challenges. Typically, iron is not the first choice when it comes to develop novel catalyst systems. The relatively higher catalyst loading and lower efficiency of the iron catalysts compared with noble metal catalysts in similar reactions limit the further applications in organic synthesis. Consequently, a thorough understanding of mechanism details will be crucial for the improvement of catalytic activity. In addition, new substrates, highly efficient iron catalysts and new types of reactions are expected to broaden the usability of cycloadditions. Furthermore, the chemoselectivity as well as the regioselectivity of the cycloaddition reaction is an urgent problem to be solved. Finally, the development of enantioselective protocols will benefit the synthesis of chiral compounds or natural products.

This work was supported by the National Natural Science Foundation of China (21172218) and the National Basic Research Program of China (2010CB833300).

1 Lautens M, Klute W, Tam W. Transition metal-mediated cycloaddition reactions. Chem Rev, 1996, 96: 49-92

2 Bolm C. A new iron age. Nat Chem, 2009, 1: 420

3 Bolm C, Legros J, Paih J L, et al. Iron-catalyzed reactions in organic synthesis. Chem Rev, 2004, 104: 6217-6254

4 Sarhan A A O, Bolm C. Iron(III) chloride in oxidative C-C coupling reactions. Chem Soc Rev, 2009, 38: 2730-2744

5 Correa A, Mancheño O G, Bolm C. Iron-catalysed carbon-heteroatom and heteroatom-heteroatom bond forming processes. Chem Soc Rev, 2008, 37: 1108-1117 
6 Díaz D D, Miranda P O, Padrón J I, et al. Recent uses of iron(III) chloride in organic synthesis. Curr Org Chem, 2006, 10: 457-476

7 Fürstner A, Martin R. Advances in iron catalyzed cross coupling reactions. Chem Lett, 2005, 34: 624-629

8 Sherry B D, Fürstner A. The promise and challenge of iron-catalzyed cross coupling. Acc Chem Rev, 2008, 41: 1500-1511

9 Sun C L, Li B J, Shi Z J. Direct C-H transformation via iron catalysis. Chem Rev, 2011, 111: 1293-1314

10 Bauer E B. Recent advances in iron catalysis in organic synthesis. Curr Org Chem, 2008, 12: 1341-1369

11 Enthaler S, Junge K, Beller M. Sustainable metal catalysis with iron: From rust to a rising star. Angew Chem Int Ed, 2008, 47: 3317-3321

12 Nakamura E, Yoshikai N. Low-valent iron-catalyzed C-C bond formation-addition, substitution, and $\mathrm{C}-\mathrm{H}$ bond activation. J Org Chem, 2010, 75: 6061-6067

13 Liu L X. Recent uses of iron catalysts in organic reactions. Curr Org Chem, 2010, 14: 1099-1126

14 Che $\mathrm{C}$ M, Zhou C Y, Wong E L M. Catalysis by Fe=X complexes (X= NR, $\mathrm{CR}_{2}$ ). Top Organomet Chem, 2011, 33: 111-138

15 Hilt G, Janikowski J. Iron-catalyzed cycloadditions and ring expansion reactions. In: Plietker B, ed. Iron Catalysis in Organic Chemistry: Reactions and Applications. New York: Wiley-VCH, 2008. 245-269

16 Hamaker C G, Mirafzal G A, Woo K L. Catalytic cyclopropanation with iron(II) complexes. Organometallics, 2001, 20: 5171-5176

17 Tagliatesta P, Pastorini A. Remarkable selectivity in the cyclopropanation reactions catalysed by a halogenated iron meso-tetraphenylporphyrin. J Mol Catal A: Chem, 2003, 198: 57-61

18 Du G, Andrioletti B, Rose E, et al. Asymmetric cyclopropanation of styrene catalyzed by chiral macrocyclic iron(II) complexes. Organometallics, 2002, 21: 4490-4495

19 Lai T S, Chan F Y, So P K, et al. Alkene cyclopropanation catalyzed by Halterman iron porphyrin: Participation of organic bases as axial ligands. Dalton Trans, 2006, 4845-4851

20 Nicolas I, Roisnel T, Maux P L, et al. Asymmetric intermolecular cyclopropanation of alkenes by diazoketones catalyzed by Halterman iron porphyrins. Tetrahedron Lett, 2009, 50: 5149-5151

21 Maux P L, Juillard S, Simonneaux G. Asymmetric synthesis of trifluoromethylphenyl cyclopropanes catalyzed by chiral metalloporphyrins. Synthesis, 2006, 1701-1704

22 Morandi B, Carreira E M. Iron-catalyzed cyclopropanation with trifluoroethylamine hydrochloride and olefins in aqueous media: In situ generation of trifluoromethyl diazomethane. Angew Chem Int Ed, 2010, 49: 938-941

23 Morandi B, Cheang J, Carreira E M. Iron-catalyzed preparation of trifluoromethyl substituted vinyl- and alkynylcyclopropanes. Org Lett, 2011, 13: 3080

24 Edulji S K, Nguyen S T. Catalytic olefin cyclopropanation using $\mu$-oxobis[(salen)iron(III)] complexes. Organometallics, 2003, 22: 3374-3381

25 Edulji S K, Nguyen S T. Substrate scope in the olefin cyclopropanation reaction catalyzed by $\mu$-oxo-bis[(salen)iron(III)] complexes. Pure Appl Chem, 2004, 76: 645-649

26 Mansuy D, Mahy J P, Dureault A, et al. Iron- and manganese-porphyrin catalysed aziridination of alkenes by tosyl- and acyl-iminoiodobenzene. Chem Commun, 1984, 1161-1163

27 Yan S Y, Wang Y, Shu Y J, et al. Nitrene transfer reaction catalyzed by substituted metallophthalocyanines. J Mol Catal A: Chem, 2006, 248: $148-151$

28 Heuss B D, Mayer M F, Dennis S, et al. Iron mediated nitrenoid transfer: $\left[\left(\eta^{5}-\mathrm{C}_{5} \mathrm{H}_{5}\right) \mathrm{Fe}(\mathrm{CO})_{2}(\mathrm{THF})\right]^{+}\left[\mathrm{BF}_{4}\right]^{-}$catalyzed aziridination of olefins. Inorg Chim Acta, 2003, 342: 301-304

29 Avenier F, Latour J M. Catalytic aziridination of olefins and amidation of thioanisole by a non-heme iron complex. Chem Commun, 2004, 1544-1545

30 Klotz K L, Slominski L M, Hull A V, et al. Non-heme iron(II) complexes are efficient olefin aziridination catalysts. Chem Commun, 2007, 2063-2065

31 Klotz K L, Slominski L M, Riemer M E, et al. Mechanism of the iron-mediated alkene aziridination reaction: Experimental and computational investigations. Inorg Chem, 2009, 48: 801-803
32 Liu P, Wong E L M, Yuen A W H, et al. Highly efficient alkene epoxidation and aziridination catalyzed by iron(II) salt+4,4',4"-trichloro$2,2^{\prime}: 6^{\prime}, 2^{\prime \prime}$-terpyridine/4,4"-Dichloro-4'-O-PEG-OCH3-2,2':6',2"-terpy ridine. Org Lett, 2008, 10: 3275-3278

33 Nakanishi M, Salit A F, Bolm C. Iron-catalyzed aziridination reactions. Adv Synth Catal, 2008, 350: 1835-1840

34 Fan R H, Pu D P, Gan J H, et al. $\mathrm{PhI}(\mathrm{OAc})_{2} / \mathrm{I}_{2}$ induced aziridination of alkenes with $\mathrm{TsNH}_{2}$ under mild conditions. Tetrahedron Lett, 2008, 49: 4925-4928

35 Mayer A C, Salit A F, Bolm C. Iron-catalysed aziridination reactions promoted by an ionic liquid. Chem Commun, 2008, 5975-5977

36 Simkhovich L, Gross Z. Iron(IV) corroles are potent catalysts for aziridination of olefins by chloramine-T. Tetrahedron Lett, 2001, 42: 8089-8092

37 Vyas R, Gao G Y, Harden J D, et al. Iron(III) porphyrin catalyzed aziridination of alkenes with bromamine-T as nitrene source. Org Lett, 2004, 6: 1907-1910

38 Liu Y G, Che C M. [Fe ${ }^{\mathrm{III}}\left(\mathrm{F}_{20}\right.$-tpp) $\left.\mathrm{Cl}\right]$ is an effective catalyst for nitrene transfer reactions and amination of saturated hydrocarbons with sulfonyl and aryl azides as nitrogen source under thermal and microwave-assisted conditions. Chem Eur J, 2010, 16: 10494-10501

39 Cramer S A, Jenkins D M. Synthesis of aziridines from alkenes and aryl azides with a reusable macrocyclic tetracarbene iron catalyst. J Am Chem Soc, 2011, 133: 19342-19345

40 Rosenblum M, Scheck D. Condensation of propiolic esters with olefins catalyzed by the $\mathrm{C}_{5} \mathrm{H}_{5} \mathrm{Fe}(\mathrm{CO})_{2}$ cation. Organometallics, 1982, 1: 397-400

41 Ohara $\mathrm{H}$, Itoh T, Nakamura M, et al. [2+2]-Cycloaddition reaction of styrene derivatives using an $\mathrm{Fe}$ (III) salt catalyst. Chem Lett, 2001, 624-625

42 Ohara H, Kiyokane H, Itoh T. Cycloaddition of styrene derivatives with quinone catalyzed by ferric ion; remarkable acceleration in an ionic liquid solvent system. Tetrahedron Lett, 2002, 43: 3041-3044

43 Bouwkamp M W, Bowman A C, Lobkovsky E, et al. Iron-catalyzed $[2 \pi+2 \pi]$ cycloaddition of $\alpha, \omega$-dienes: The importance of redox-active supporting ligands. J Am Chem Soc, 2006, 128: 13340-13341

44 Russell S K, Lobkovsky E, Chirik P J. Iron-catalyzed intermolecular $[2 \pi+2 \pi]$ cycloaddition. J Am Chem Soc, 2011, 133: 8858-8861

45 Eaton B E, Rollman B. The first catalytic iron-mediated [4+1] cyclopentenone assembly: Stereoselective synthesis of 2,5-diakylidenecyclo3-pentenones. J Am Chem Soc, 1992, 114: 6245-6246

46 Sigman M S, Kerr C E, Eaton B E. Catalytic iron-mediated carbonoxygen and carbon-carbon bond formation in [4+1] assembly of alkylidenebutenolides. J Am Chem Soc, 1993, 115: 7545-7546

47 Sigman M S, Eaton B E. The first iron-mediated catalytic carbon-nitrogen bond formation: [4+1] cycloaddition of allenyl imines and carbon monoxide. J Org Chem, 1994, 59: 7488-7491

48 Sigman M S, Eaton B E. Catalytic iron-mediated [4+1] cycloaddition of diallenes with carbon monoxide. J Am Chem Soc, 1996, 118: 11783-11788

49 Sigman M S, Eaton B E. Low-temperature study of the iron-mediated [4+1] cyclization of allenyl ketones with carbon monoxide. Organometallics, 1996, 15: 2829-2832

50 Knölker H J, Braier A, Bröcher D J, et al. Transition metal complexes in organic synthesis. Part 55: Synthesis of corannulene via an iron- mediated $[2+2+1]$ cycloaddition. Tetrahedron Lett, 1999, 40: 8075-8078

51 Knölker H J, Cämmerer S. Transition metal complexes in organic synthesis. Part 62: Total synthesis of $( \pm)$-demethoxycarbonyldihydrogambirtannine and norketoyobyrine by an iron-mediated $[2+2+1]$ cycloaddition. Tetrahedron Lett, 2000, 41: 5035-5038

52 Imhof W, Anders E, Göbel A, et al. A theoretical study on the complete catalytic cycle of the hetero-Pauson-Khand-type $[2+2+1]$ cycloaddition reaction of ketimines, carbon monoxide and ethylene catalyzed by iron carbonyl complexes. Chem Eur J, 2003, 9: 1166-1181

53 Imhof W, Anders E. Regioselectivity in iron-catalyzed [2+2+1] cycloadditions: A DFT investigation of substituent effects in 1,4-diazabutadienes. Chem Eur J, 2004, 10: 5717-5729

54 Chen T, Jiang S C, Turos E. Allylation and [3+2] cycloaddition reactions of imines with allyl(cyclopentadienyl)iron(II) dicarbonyl complexes. Tetrahedron Lett, 1994, 35: 8325-8328

55 Ipaktschi J, Halimehjani A Z, Saidi M R. Investigation of the reaction of allyl(cyclopentadienyl)iron(II) dicarbonyl with iminium salts: Syn- 
thesis of ammonium salts of substituted five-membered-ring iron complexes. Organometallics, 2007, 26: 201-203

56 Kerber R C, Garcia R, Nobre A L. Cycloaddition reactions of dicarbonyl $\left(\eta^{5}\right.$-cyclopentadienyl $)\left(\eta^{1}\right.$-indenyl)iron. Organometallics, 1996, 15: $5756-5758$

57 Fan J M, Gao L F, Wang Z Y. Facile construction of highly functionalized 2-pyrrolines via $\mathrm{FeCl}_{3}$-catalyzed reaction of aziridines with arylalkynes. Chem Commun, 2009, 5021-5023

58 Viton F, Bernardinelli G, Kündig E P. Iron and ruthenium Lewis acid catalyzed asymmetric 1,3-dipolar cycloaddition reactions between nitrones and enals. J Am Chem Soc, 2002, 124: 4968-4969

59 Bãdoiu A, Bernardinelli G, Mareda J, et al. Iron- and rutheniumLewis acid catalyzed asymmetric 1,3-dipolar cycloaddition reactions between enals and diaryl nitrones. Chem Asian J, 2008, 3: 1298-1311

60 Wu H S, Wang B, Liu H Q, et al. A novel Fe(II)/diaryl prolinol catalyzed asymmetric 1,3-dipolar cycloaddition of azomethine ylides with alkenes. Tetrahedron, 2011, 67: 1210-1215

61 Domínguez G, Pérez-Castells J. Recent advances in [2+2+2] cycloaddition reactions. Chem Soc Rev, 2011, 40: 3430-3444

62 Weding N, Hapke M. Preparation and synthetic applications of alkene complexes of group 9 transition metals in $[2+2+2]$ cycloaddition reactions. Chem Soc Rev, 2011, 40: 4525-4538

63 Shaaban M R, El-Sayed E, Elwahy A H M. Construction of fused heterocycles by metal-mediated $[2+2+2]$ cyclotrimerization of alkynes and/or nitriles. Tetrahedron, 2011, 67: 6059-6130

64 Pla-Quintana A, Roglans A. [2+2+2] Cycloaddition reactions of macrocyclic systems catalyzed by transition metals, a review. Molecules, 2010, 15: 9230-9251

65 Wang C X, Li X C, Xu F, et al. Synthesis of pyridine derivatives via transition metal-catalyzed $[2+2+2]$ cycloaddition. Prog Chem, 2010, 22: $610-630$

66 Tanaka K. Transition-metal-catalyzed enantioselective [2+2+2] cycloadditions for the synthesis of axially chiral biaryls. Chem Asian J, 2009, 4: 508-518

67 Varela J A, Saá C. Recent advances in the synthesis of pyridines by transition-metal-catalyzed [2+2+2] cycloaddition. Synlett, 2008, 17: 2571-2578

68 Galan B R, Rovis T. Beyond reppe: Building substituted arenes by [2+2+2] cycloadditions of alkynes. Angew Chem Int Ed, 2009, 48: 2830-2834

69 Shibata T, Tsuchikama K. Recent advances in enantioselective [2+2+2] cycloaddition. Org Biomol Chem, 2008, 6: 1317-1323

70 Heller B, Hapke M. The fascinating construction of pyridine ring systems by transition metal-catalysed $[2+2+2]$ cycloaddition reactions. Chem Soc Rev, 2007, 36: 1085-1094

71 Maryanoff B E, Zhang H C. Pyridine-containing macrocycles via cobalt-mediated $[2+2+2]$ cycloadditions of $\alpha, \omega$-bis-alkynes. Arkivoc, 2007, xii: 7-35

72 Chopade P R, Louie J. [2+2+2] Cycloaddition reactions catalyzed by transition metal complexes. Adv Synth Catal, 2006, 348: 2307-2327

73 Kotha S, Brahmachary E, Lahiri K. Transition metal catalyzed $[2+2+2]$ cycloaddition and application in organic synthesis. Eur J Org Chem, 2005: 4741-4767

74 Varela J A, Saá C. Construction of pyridine rings by metal-mediated [2+2+2] cycloaddition. Chem Rev, 2003, 103: 3787-3801

75 Breschi C, Piparo L, Pertici P, et al. ( $\eta^{6}$-Cyclohepta-1,3,5-triene) ( $\eta^{4}$-cycloocta-1,5-diene)iron(0) complex as attractive precursor in catalysis. J Organomet Chem, 2000, 607: 57-63

76 Liu Y B, Yan X Y, Yang N F, et al. Highly regioselective cyclotrimerization of terminal alkynes catalyzed by $\mathrm{Fe}(\mathrm{II})$ complexes bearing 2-(benzimidazolyl)-6-(1-(arylimino)ethyl)pyridines. Catal Commun, 2011, 12: 489-492

77 Saino N, Kogure D, Okamoto S. Intramolecular cyclotrimerization of triynes catalyzed by $N$-heterocyclic carbene- $\mathrm{CoCl}_{2} / \mathrm{Zn}$ or $-\mathrm{FeCl}_{3} / \mathrm{Zn}$. Org Lett, 2005, 7: 3065-3067

78 Saino N, Kogure D, Kase K, et al. Iron-catalyzed intramolecular cyclotrimerization of triynes to annulated benzenes. J Organomet Chem, 2006, 691: 3129-3136
79 Fürstner A, Majima K, Matín R, et al. A cheap metal for a "noble" task: Preparative and mechanistic aspects of cycloisomerization and cycloaddition reactions catalyzed by low-valent iron complexes. J Am Chem Soc, 2008, 130: 1992-2004

80 Knoch F, Kremer F, Schmidt U, et al. $\left(\eta^{4}-1,5-\right.$ Cyclooctadiene $)\left(\eta^{6}-\right.$ phosphinine)iron(0): Novel room-temperature catalyst for pyridine formation. Organometallics, 1996, 15: 2713-2719

81 Ferré K, Toupet L, Guerchais V. Alkyne coupling reactions mediated by iron(II) complexes: Highly chemo- and regioselective formation of $\eta^{6}$-coordinated arene and pyridine complexes. Organometallics, 2002, 21: 2578-2580

82 Wang C X, Li X C, Wu F, et al. A simple and highly efficient iron catalyst for a $[2+2+2]$ cycloaddition to form pyridines. Angew Chem Int Ed, 2011, 50: 7162-7166

83 D'Souza B R, Lane T K, Louie J. Iron-catalyzed cycloaddition of alkynenitriles and alkynes. Org Lett, 2011, 13: 2936-2939

84 Corey E J, Imai N, Zhang H Y. Designed catalyst for enantioselective Diels-Alder addition from a $C_{2}$-symmetric chiral bis(oxazoline)Fe(III) complex. J Am Chem Soc, 1991, 113: 728-729

85 Sibi M P, Manyem S, Palencia H. Fluxional additives: A second generation control in enantioselective catalysis. J Am Chem Soc, 2006, 128: 13660-13661

86 Kanemasa S, Oderaotoshi Y, Yamamoto H, et al. Cationic aqua complexes of the $C_{2}$-symmetric trans-chelating ligand $(R, R)-4,6$-dibenzofurandiyl-2,2'-bis(4-phenyloxazoline). Absolute chiral induction in Diels-Alder reactions catalyzed by water-tolerant enantiopure Lewis acids. J Org Chem, 1997, 62: 6454-6455

87 Kanemasa S, Oderaotoshi Y, Sakaguchi S, et al. Transition-metal aqua complexes of 4,6-dibenzofurandiyl-2,2'-bis(4-phenyloxazoline). Effective catalysis in Diels-Alder reactions showing excellent enantioselectivity, extreme chiral amplification, and high tolerance to water, alcohols, amines, and acids. J Am Chem Soc, 1998, 120: 3074-3088

88 Matsukawa S, Sugama H, Imamoto T. Synthesis of P-chirogenic diphosphine oxides and their use in catalytic asymmetric Diels-Alder reaction. Tetrahedron Lett, 2000, 41: 6461-6465

89 Khiar N, Fernández I, Alcudia F. $C_{2}$-symmetric bis-sulfoxides as chiral ligands in metal catalysed asymmetric Diels-Alder reactions. Tetrahedron Lett, 1993, 34: 123-126

90 Usuda H, Kuramochi A, Kanai M, et al. Challenge toward structural complexity using asymmetric catalysis: Target-oriented development of catalytic enantioselective Diels-Alder reaction. Org Lett, 2004, 6: 4387-4390

91 Shimizu Y, Shi S L, Usuda H, et al. Catalytic asymmetric total synthesis of ent-hyperforin. Angew Chem Int Ed, 2010, 49: 1103-1106

92 Shimizu Y, Shi S L, Usuda H, et al. The first catalytic asymmetric total synthesis of ent-hyperforin. Tetrahedron, 2010, 66: 6569-6584

93 Kündig E P, Bourdin B, Bernardineli G. Asymmetric Diels-Alder reactions catalyzed by a chiral iron Lewis acid. Angew Chem Int Ed Engl, 1994, 33: 1856-1858

94 Bruin M E, Kündig E P. A new chiral ligand for the Fe-Lewis acid catalysed asymmetric Diels-Alder reaction. Chem Commun, 1998, 2635-2636

95 Kündig E P, Saudan C M, Viton F. Chiral cyclopentadienyl-iron and -ruthenium Lewis acids containing the electron-poor BIPHOP-F ligand: A comparison as catalysts in an asymmetric Diels-Alder reaction. Adv Synth Catal, 2001, 343: 51-56

96 Bakhtiar R, Drader J J, Jacobson D B. Iron-mediated [4+2] cycloaddition of 1,3-butadiene with ethyne and propyne in the gas phase. $\mathrm{J}$ Am Chem Soc, 1992, 114: 8304-8307

97 Darbasie N D, Schnatter W F K, Warner K F, et al. The cycloaddition reactions of 2-ethoxy-3-phenylvinylketene iron( $(0)$ with alkynes to yield catechol derivatives. Tetrahedron Lett, 2006, 47: 963-966

98 Truong J, Caze V, Akhani R K, et al. Halogenated catechols from cycloaddition reactions of $\eta^{4}$-(2-ethoxyvinylketene)iron(0) complexes with 1-haloalkynes. Tetrahedron Lett, 2010, 51: 921-923

99 Pellissier H. Recent developments in the [5+2] cycloaddition. Adv Syn Catal, 2011, 353: 189-218

Open Access This article is distributed under the terms of the Creative Commons Attribution License which permits any use, distribution, and reproduction in any medium, provided the original author(s) and source are credited. 